
June, 2017

\title{
When we talk about older people in HCI, who are we talking about? Towards a 'turn to community' in the design of technologies for a growing ageing population
}

\author{
Valeria Righi $^{\mathrm{a}^{*}} \quad$ Sergio Sayago $^{\mathrm{b}} \quad$ Josep Blat $^{\mathrm{a}}$ \\ ${ }^{a}$ Interactive Technologies Group, Universitat Pompeu Fabra, Roc Boronat, 138, 08018, Barcelona, Spain. \\ (valeria.righi, josep.blat)@upf.edu \\ ${ }^{\mathrm{b}}$ Departament de Matemàtiques i Informàtica, Universitat de Barcelona, Gran Via de les Corts Catalanes, \\ 585,08007 Barcelona. sergiosayago@ub.edu \\ ${ }^{*}$ Corresponding author
}

\begin{abstract}
This paper addresses a number of challenges HCI designers and researchers deal with when designing digital technologies for older people. We conducted a 5-year research-through-design study, which combined ethnography, participatory design and real-life evaluation, to explore the design and use of technologies aimed to enhance the social life of older people. The paper explores widespread assumptions about the social category of older people and the meaning of technologies for them. This paper argues that assuming that (i) older people have unique needs and interests that set them apart from other user groups and (ii) the meaning of technologies remains unaltered on completion of co-design activities are both problematic, because they do not consider carefully enough the sociocultural contexts in which older people interact and engage in their daily lives. The paper posits that the meaning of technologies for older people and their own identities as individuals of a certain age are shaped within situated communities. Thus, technologies designed 'for older people' should be designed to meet situated and dynamic needs/interests of the communities (and not only of care) to which they belong. We draw upon our findings and other situated epistemological discourses in HCI to introduce a different perspective, a turn to community, in the design of technologies for an ever-increasing ageing population.
\end{abstract}

Keywords: older people, research-through-design, ethnography, communities, appropriation, practices, situated epistemology

\section{Introduction}

Let us start this paper by asking you to imagine that you are working with other Human-Computer Interaction (HCI) designers and researchers on a Research \& Development (R\&D) project aimed to design interactive technologies for older people. During the course of the project, you will address important and unavoidable questions. Of particular importance for the purpose of this paper are the following two: (i) how do you conceptualize older people in the project (e.g., as homebound and frail elderly people or socially active individuals)? (ii) What interactive technologies do they truly need, and why? By addressing these questions, you will define and limit the design space (McLean et al., 1991), within which research and design decisions will be made throughout the project. In this decision-making process, designers and researchers will construct their own meanings of old age and bring them into their activities (Peine et al., 2014). Consequently, the digital artefacts designed in the project will exhibit implicit models of their intended users and expected activities (Bijker et al., 1989; Carroll et al., 2001).

Older people have been conceptualized in two very different ways in HCI research and design studies. The most predominant one sees older people as individuals in need of help, due to the impact of age-related declines in functional abilities on their everyday lives, and with little or a lack of experience of using Information and Communication Technologies (ICTs). This way of operationalizing older people falls into the first wave of HCI research, which focuses on Ergonomics / Human Factors (Bannon, 1991). 
Compensating for "the downsides of ageing" (Rogers et al., 2014) is therefore the most important design criterion to create technologies for older people. These technologies are primarily aimed to help them conduct a wide range of ADL (Activities of Daily Living) and IADLs (Instrumental Activities of Daily Living) on their own. Assistive Technologies are a noteworthy example. By contrast, a growing number of studies aim to foster a more positive view of old age. Older people are portrayed as individuals who are able to use ICTs and make important contributions to their families and society despite their age (e.g., Carroll et al., 2011; Rogers et al., 2014). Thus, social relationships, personal interests and aspirations, as well as agerelated declines in functional capabilities, come into play in the design of technologies, which are intended to foster, for instance, social interaction and inclusion, empowerment and creativity, which are topics being examined within the third (or current) HCI wave (Bødker, 2006).

Both conceptualizations might lead us to believe that older people belong to a well-defined category of users. In HCI, one needs to define (somehow) who the user is, and older people tend to be regarded as individuals who are above a certain age limit and that exhibit similar traits. Consequently, most HCI work portrays older people as being considerably different from other categories of users (Gregor and Newell, 2001). This is evident in most HCI studies conducted under laboratory conditions (e.g., Trewin et al., 2012), wherein older people are design subjects. A growing number of recent studies are adopting a more participatory approach to working with older people, who can be seen as design partners (Hornung et al.,2017; McNeill et al., 2017). Yet, in this paper, we argue that the fundamental problem of this categorization, which focuses on addressing specific aspects that are almost universally attributed to the category of older people, is that designers, even when adopting a more participatory approach, might fail to think of older people as ordinary members of (multiple) communities, wherein they interact with other (younger, peer and older) members for a wide range of purposes, and shape their own identity.

We draw upon a 5-year research-through design study conducted within the context of two R\&D projects: (a) Life 2.0, which was aimed at developing new social and peer-to-peer services for older people, and (b) WorthPlay, which was designed to understand and develop meaningful, playable and appealing digital games for older people. We conducted both projects in a lifelong learning community. In both projects, we initially defined older people as individuals aged 65-75. We also wanted to capitalize on positive images of old age. 390 people (hereinafter, participants) aged 55-81 took part in a wide range of research and co-design activities. Yet, participants seldom adopted the technologies that we developed as a result of the participatory design process. Rather, they re-interpreted the technologies in order to (a) meet their real interests, which evolved as the study progressed, and (b) incorporate them into the everyday practices they conducted in the lifelong learning community to which they belonged. We argue that the problem was that the study failed to recognize that our participants identified themselves more as members of the learning community than as representatives of the social category of 'older people'. This prompted us to reflect on: i) the role that community could have played in the design process, especially in helping us formulate the design space, and ii) the (social) appropriation and integration of the technologies developed in the community.

This paper introduces a different perspective, which we term 'turn to community', , on HCI design and research, in particular with older people, in order to:

(a) re-think the subject of design, by moving from designing "for older people" to designing for "situated communities" to which they belong and where technologies are shaped and appropriated,

(b) shift the current focus of HCI research and design with older people, from defining the features of a technological artefact based on their well-known characteristics and expected needs to fostering a dynamic and mutually-shaping relationship between technologies and their everyday practices.

Adopting a turn to community focus rests upon conducting research and design activities in those communities in which older people dynamically and contingently act in their everyday lives ${ }^{2}$, rather than set

\footnotetext{
${ }^{1}$ Perspective as used in this paper borrows the definition "the assumptions about a phenomenon being studied or designed for, the lenses used to analyze it and the questions asked" (Rogers 2012, p. 4). We are aware of the fact that using the rhetorical device of a turn, which became "popularized as a way of noting a change in the framing of HCI ever since the phrase 'turn to the social' was coined in the 1990s" (ibid, p. 68), in naming this perspective might be regarded as too strong, given that it is not supported by other empirical evidence than that provided in the article. Yet, we have used this term in an attempt to foster a change in the framing of HCI with older people by speaking a lingua franca.
} 
up a user group by relying on chronological age as the main inclusion / exclusion criteria. The design space also needs to be reformulated in terms of communities' needs, practices and expectations. Of particular importance of the turn to community introduced in this paper is the ability to participate in a community over an extended period of time, even when a research project has come to an end. This community engagement is instrumental in understanding the adoption of the technologies developed, and we show examples of how the novel technologies developed in Life 2.0 and WorthPlay were turned into novel community practices, sometimes supported by widespread technologies.

Adopting a turn to community also invites us to re-think about the use of the term 'design for older people', which, we argue, does not do justice to the well-documented heterogeneity assigned to this category. Also, this term may no longer be adequate, especially when working with communities to which people of different ages belong. Finally, a turn to community is also an invitation to re-define the object of our design activity: not only should the goal be to create digital artefacts that respond to a set of defined users' needs, but also to create situations wherein dialogues between existing everyday practices and new technologies occur and result in new technology-mediated practices, challenges, and needs.

\section{Related works}

In this section we aim to provide a more detailed account of the works in the areas mentioned in the Introduction. In 2.1, we review and discuss the two strands that have hitherto characterized the discourse on developing technologies for older people within HCI. In 2.2, we provide an overview of the diverse interpretations of the term older people in the field of HCI and related ones, such as Design and Social Gerontology.

\subsection{Two approaches towards designing technologies for/ with older people}

\subsubsection{The compensation model and related design scenarios}

In the 1990s, the Human Factors Research Needs for an Aging Population report (Czaja, 1990) and the Handbook of Human Factors and the Older Adults (Fisk and Rogers, 1997) pointed out that society had done little to prepare itself for the unprecedented development of the ageing phenomenon, and that new interfaces which compensated for the impact of age-related changes in functional abilities on a wide range of areas beyond ICT (e.g., transportation and home) were needed. According to these two seminal works, getting a deeper insight into the implications of the aging process in the design of systems and including older people in design developments could help us design 'age-friendly' user interfaces.

Since the publication of these two highly influential works, a large number of studies have regarded both chronological age and age-related changes in functional abilities as the main influential factors in the design of technologies for older people. Drawing upon a discourse analysis of 644 archived SIGCHI papers published over the last three decades related to ageing, Vines et al argue that, within this body of knowledge, "it is emphasized that there is a need to understand the deficits that come with age in order to design interfaces, systems, and services that are inclusive and easy for older people to learn and use" (2015, p. 14). In a parallel and interrelated trend, technologies designed to help older people to conduct a wide range of (everyday) activities have been developed. Assistive Technologies, ranging from memory aids (Lawson, Nutter, \& Wilson, 2007) to exergames, which try to improve balance and reduce risks of falls (Gerling, Schild, \& Masuch, 2010), are a noteworthy example of this design approach.

\subsubsection{Dispelling stereotypes; empowering and inclusive design scenarios}

The compensation model has been criticised for focusing almost exclusively on the 'downside of ageing', which tends to portray older people as passive recipients of technologies (Rogers \& Marsden, 2013). Furthermore, (Peine et al., 2014) claim that the design of technologies has mostly been focused on the "agerelated handicaps and problems not because they are necessarily dominant in the lives of older persons, but because they can so neatly be translated into needs and then design requirements". What other aspects do characterize older people's lives?

\footnotetext{
${ }^{2}$ These communities are often made up of people of several age ranges.
} 
A growing number of recent studies have argued for considering different ways of growing older and exploring other aspects than age-related declines as a primary source for design. Through an extensive ethnographic study of ICT use by older people, (Sayago, 2009) proposed a change of paradigm in HCI research with the older population, moving from regarding older people as a set of human factors towards thinking of them as social actors, a term that stresses their highly social use of ICTs. Within this paradigm, compensating for diminishing abilities is not the cornerstone of research / design efforts. By drawing upon a literature review of research conducted in the fields of Gerontology, Gerontechnology, HCI and Government policy, Durick et al (2013) dispel a number of myths about older people when it comes to digital technologies, such as older people being i) a homogeneous user group, ii) socially isolated and lonely, iii) unable to use technologies and iv) incapable of learning mainstream technologies. By revisiting common (and mostly negative) assumptions about ageing, a number of studies have explored new technologies that capitalize on aspects of older people's social lives, such as digital games that support engagement between grandchildren and grandparents (Khoo et al. 2009) or mobile applications that support social interaction among friends and organization of outdoor activities (Malmborg \& Yndigegn, 2013). More recently, older people's creativity and ingenuity has been explored as a source for co-creating technologies (e.g., (Rogers et al. 2014), (Lee, 2012)).

\section{2 "Older people", a term with diverse interpretations}

\subsubsection{Homogeneity, heterogeneity, and everything in between}

Who are older people? 'Know thy user' is key in good HCI research, thus this question is of paramount importance. The answer, however, is more elusive. Older people are generally defined, within HCI and other strongly related disciplines, such as Psychology, as people aged 60 and beyond. HCI researchers have also acknowledged that older people are a highly heterogeneous user group, especially as far as their experiences, abilities, health status and skills are concerned (Gregor et al. 2002; Czaja and Lee, 2007, Fisk et al., 2009, Hill et al., 2015). However, previous works have also argued that a large number of HCI studies portray them as a homogeneous category, i.e., a user group with common interests, abilities and needs (e.g. Gaver, 2010; Vines, 2015; Light et al., 2015, Durick et. al, 2013).

Both discourses are problematic. On the one hand, homogeneity encourages us to characterize the group of older people according to a fairly common set of needs, interests and abilities. This homogeneity does not take into account the wide diversity of their life experiences, which can determine interests, attitudes towards, and motivations for, using ICTs. On the other hand, the heterogeneous discourse, which provides a more realistic picture of older people, seems to assume that older people belong to an easy-to-define category. For instance, some studies regard chronological age as the main including/excluding criterion, while others focus on abilities (Gregor et al. 2002), on life stages ${ }^{3}$ (Laslett, 1991), or on transitions between different life stages (Wildevuur et al., 2013).

If we move from HCI to sociological disciplines, the definition of the category of older people is much more faceted. For instance, social and cultural gerontologists ${ }^{4}$ contend that old age is a social construct defined by everyday practices and discourses (Degnen, 2007; Phillipson, 2008, Peine et al., 2015). Moreover, studies informed by social constructionism theories (e.g. Bijker et al., 1989) have showed that designers and developers often build their own representations of older people. These representations might not always correspond to the self-identity of their participants, and this can potentially undermine technology acceptance (Compagna and Kohlbacher, 2015; Hyysalo, 2006; Neven, 2015; Östlund et al., 2015; Peine et al., 2014).

\subsubsection{Constructing alternatives}

\footnotetext{
${ }^{3}$ (Laslett, 1991) proposed one of the most influential classifications of life stages. The First Age starts at birth and is characterized by dependence on others, socialization and education. The Second Age refers to the period of maturity, independence, familiar and social responsibilities. People enter the Third Age when approaching full or part-time retirement and when career responsibilities are no longer a central part of life. The Fourth Age is characterized by relying on others for support and help. The Fourth Age is a period of severe illness and disabilities.

${ }^{4}$ Within the field of Gerontology, the use of 'older people' as a category has been widely discussed and questioned, on the grounds that the experience of being old is not only determined by biological or chronological age (e.g. 60 / 65), which seems to predominate in the current discourse on HCI, but by a myriad of other aspects, ranging from biographical, socio economical, political, and cultural ones (see, for instance, Walker, 1981; Bytheway, 1997; Joyce \& Mamo, 2006, Lund and Engelsrud, 2008, Bengston et al., 2009).
} 
Only recently has the field of HCI started to discuss "alternative ways of representing older people in our communities' publications that better capture the diversity that comes with old age" (Vines et al., 2015 p.18). Brandt et al., (2010) proposed the concepts of 'communities of everyday practice' and 'situated elderliness' as a way to approach older people. Instead of recruiting individuals based on their chronological age, they suggest approaching communities of everyday practices, where "seniors are skilfully enacting everyday practices as seniors", because when growing older, people might experience situated elderliness (i.e., difficulties in conducting some activities while being able to handle well other situations in their everyday life) and their need to belong to a community might therefore increase.

As mentioned before, other scholars have opted for a life-span perspective, drawing upon the concept of life stages. In a study of furniture design, designers approached the wide heterogeneity of the older participants by relying on the concepts of third and fourth age. In particular, they selected four different samples of participants based on their housing situations, which were related to a particular life stage, i.e., living in a nursing home, recently moved to senior housing, had lived in senior housing for at least three years, had not moved at all for many years (Jonsson, 2013; cited in Östlund et al., 2015). A more dynamic view of life stages is proposed by (Wildevuur et al., 2013), wherein it is distinguished between three life stages (retirement, illness \& disabilities and loss of loved ones), and stressed their transitions as related to the risk of getting disconnected, e.g., from the professional, social and family life. Thus, they invite us to look at these transitions to design for connectedness. In a similar vein (Salovaara et al., 2010) focused on the late middle-aged people (age range 55-65) to understand what role technology plays in helping them to cope with life transitions. Their analysis highlights the need to consider late middle-agers as individuals acting in various communities/networks (e.g., relatives belonging to different generations, friends, members of hobby groups, former work colleagues, etc.).

By considering life stages and life transitions, we can go beyond chronological age and focus more on life experiences and everyday needs strongly related to the lessons learned over a person's lifetime, such as connectedness. However, only those experiences and needs related to a particular life stage are considered. For example, if we aim to enhance Computer-Mediated Communication between grandchildren and grandparents, the "aged life stage" might not help us to achieve our objective. Grandparents might be in different life stages (e.g., retired or active workers). Yet, they share common interests and goals, which are typical of grandparenthood. These common interests could drive the design goals in a more effective way than do their actual life stages. Framing ageing by understanding commonalities between groups of participants can potentially help us to overcome the age-based approach. The life transitions approach, which focuses on experiences and related needs, along with the communities of everyday practice (Brandt et al., 2010) and the networks of individuals (Salovaara et al., 2010) can help us to do so. In this paper, we aim to overcome the age-based approach in HCI design for older people by taking forward these three approaches.

\section{A 5-year research-through-design study}

The results presented in this paper are grounded in a research-through-design study, wherein we conducted ethnographic, design and evaluation activities in two R\&D projects, Life 2.0 and WorthPlay, over a 5-year period. The ethnographic study aimed to gain a first-hand understanding of (i) the ICT practices and everyday lives of active older people with mild-to-moderate age-related changes in functional abilities, and (ii) the local neighbourhood in which the research activities were conducted. Life 2.0 was a 3-year project partially funded by the European Commission. Public universities, IT companies and associations of older people from four European countries (Spain, Italy, Finland and Denmark) took part in the project, whose main objective was to generate new services that enable independent living of older people by connecting them with people living in their local area and offering new opportunities for social interaction. WorthPlay was an international project intended to conceptualize, design, and evaluate digital games that are sufficiently appealing, meaningful, and playable in the everyday lives of older people. Both projects were targeted at active and healthy people aged 65-75. Both projects were also roughly structured into three phases: analysis \& conceptualization, participatory design, and evaluation.

\subsection{Setting, recruitment strategies, and participants}


We conducted our research-through-design study in Àgora ${ }^{5}$, a not-for-profit organization which emerged from a grassroots initiative in the late 1980s in the district of La Verneda-St. Martí in Barcelona (Spain). Àgora (AG) aims at promoting education amongst those people living in the local area who are at risk of social exclusion, such as immigrants, people coming from schooling failure, older and disabled people. Working towards this goal, AG offers a broad array of free courses, such as foreign languages, computers and the Internet, literacy, and economics. AG was a partner in both projects and their main role was to identify potentially interested people among its members, contact them, and define recruitment and engagement strategies.

Given the educational aspect of AG, we adopted three main strategies to recruit participants: i) participate in on-going courses in AG in order to conduct in them extra-curriculum activities related to specific project's phases (e.g., co-design, evaluation activities); ii) set up new ICT classes on topics related to our research goals, and iii) run activities in public events organized by AG and attended by its members as well as people living in the local area. This recruitment strategy led us to gain knowledge of and engage with the different sub-groups that constitute the AG community.

Overall, 390 participants took part in the study. Of them, 120 participated in Life 2.0, 310 in WorthPlay, and about 40 in both projects. Approximately $40 \%$ of the participants were fairly engaged in the research and design activities - 28 participated over the entire duration of the study, while 128 took part during periods of approximately 6 months. The remaining $60 \%$ of the participants engaged sporadically in two or three activities. Participants aged 55 - 81 (average 68). The overwhelming majority of them had attained primary education. They had a wide diversity of interests, life experience and ICT expertise. There were participants who were interested in arts and literature and attended reading clubs and arts gatherings, while others were more into languages and attended English or Catalan classes. There were also about 40 older women who did not have the opportunity to go to primary school when they were children and that were now attending basic literacy courses in which they learned reading skills, basic notions of mathematics and geography. Slightly more than half of the participants $(65 \%)$ attended ICTs courses because they were interested in keeping up with the times or in brushing up on aspects they had learned in their jobs. The rest of the participants (35\%) did not take ICT courses because they were not interested in computers. The vast majority of the participants were able to conduct daily living activities on their own. Most of them participated in several cultural and physical activities (e.g., singing, dancing and hiking) in addition to attending AG classes on a weekly basis. While our participants cannot be regarded as 'vulnerable', there were bereavements and some long absences from people who experienced health problems throughout the study.

\subsection{WorthPlay and Life 2.0: rapid ethnography, PD, and real-life evaluation}

In both projects, we conducted (i) rapid ethnography in the phase of analysis, (ii) Participatory Design (PD) in the design conceptualization, and (iii) design-in-use and participant observations in the evaluation of the prototypes. Appendix I presents a full list and description of these activities.

\section{Analysis: rapid ethnography}

We grounded the PD process on rapid ethnographic studies (Millen, 2000) in an attempt to understand the daily practices of our participants and explore design opportunities. The rapid ethnographic studies were conducted during the first 6 months of each project. These studies aimed at understanding, through first-hand observations and informal conversations, participants' everyday lives, use of ICT (in Life 2.0), and their gameplay practices (in Worthplay). In Life 2.0, we conducted participant observations (DeWalt \& DeWalt, 2010) in 6 ICT classes, ran focus groups and conducted informal, face-to-face interviews, and handed diaries to participants to gather information about their daily routines. In WorthPlay, we set up an open Playing $C l u b$ in which people interested in playing games met weekly to play a variety of digital and tabletops games chosen by them and / or by the research team. We also attended 8 courses in which we proposed participants to play games related to the topics (e.g., literature) addressed in them.

\section{Conceptualization: participatory design}

The rapid ethnographic studies helped us outline the design concept of the service (in Life2.0) and the game (in Worthplay). In Life 2.0, the results highlighted two common threads in the four countries: older people

\footnotetext{
${ }^{5}$ http://edaverneda.org
} 
value socialization and want to be independent (i.e., not to rely on anyone else to conduct everyday activities). The latter was often achieved by sharing support among their networks of friends. By drawing upon these results, we conducted 2 PD workshops to create a design concept with some AG members. A PD workshop was also conducted among project partners to put together the results of the local PD activities and define a common design concept that matched the different results. The selected design concept was a social networking platform, which enables older people to offer their knowledge and skills to neighbours (i.e., a Mutual Help service), and to keep abreast of social events, commercial services and assistance available in their local area. While developing and evaluating the use that our participants made of the platform, we further reinterpreted and adapted the design concept by adopting a design-in-use approach, which considers that each use situation can be regarded as a potential design situation (Bjögvinsson et al, 2012). In order to support this design-in-use process and to encourage the uptake of the platform that we were developing, and because the results of the ethnographic study and the PD activities highlighted the importance of trust to foster sharing practices in the Mutual Help service, we established a core group of 18 participants which we met weekly in the AG computer room. The meetings were structured as regular ICT courses in which participants learned to use a variety of technologies, interacted with prototypes of the service, and were encouraged to share help among each other. These weekly meetings were aimed at informing both the ongoing design and development of the platform and the evaluation stage. In this paper we focus on how the initial design concept has evolved and been reinterpreted over the course of the project ${ }^{6}$, which encouraged us to reflect on the assumptions and conceptualization that researchers/designers bring into the design process.

The results of the rapid ethnographic study in WorthPlay pointed out that the digital games that are meaningful for our participants were predominately those that were (a) easy to personalize, (b) casual and knowledge-based games. To translate these insights into a game concept, we carried out 9 PD sessions with approximately 100 participants over a 2 -month period. The sessions were conducted in playful activities, in which participants were invited to create and / or play games which were meaningful to them. Games were simulated by using papers, posts-its and MS PowerPoint presentations As a result of the whole PD process, we developed an online gaming platform ${ }^{7}$, which allows older people (and members of their social circles) to both create and play different types of online quiz games.

\section{Evaluation}

Evaluation in Life 2.0 lasted approximately 20 months. The evaluation was designed to assess participants' attitudes towards and use of the proposed services over time, i.e., whether the participants would (and could) incorporate Mutual Help practices in their lives, and, if they did so, identify the benefits they derived from using the service. We were also interested in understanding the sustainability of the Mutual Help platform and the actors that could foster a sustained use of it. Evaluation was conducted through immersive data collection methods, which consisted of observing and talking with a core group of 18 participants during the aforementioned weekly meetings, during which they evaluated the functionality and usability of the platform prototypes. Participants also tried to figure out how they could incorporate the platform into their daily practices. We took advantage of dissemination activities conducted in the project so as to receive feedback from other people who had not previously been involved in the project, as well as a number of stakeholders from public, private and NGOs sectors.

The evaluation in WorthPlay was conducted over a 3-month period in playful sessions, which were carried out in four courses and one public event in AG. Participants were invited to create and play games by using the online gaming platform developed in the project. We did not aim at evaluating exclusively the usability of the platform, since we had done so during the PD activities. Instead, we were interested in evaluating the worthiness of the concept of the game proposed: a gaming platform for creating and playing knowledgebased games.

\subsection{Beyond, and running in parallel to, the projects: a long-term ethnographic study}

Over a 5-year period, and running in parallel to the projects, the first author of this paper was also engaged in other activities conducted in $\mathrm{AG}$ so as to gain a deeper understanding of the community, the local

\footnotetext{
${ }^{6}$ From now on, the paper reports only on the results of the Spanish study, which was coordinated by the authors.

${ }^{7}$ http://worthplay.upf.edu/game/
} 
neighbourhood, and facets of the participants' everyday life and ICT use. To this end, we adopted a classical ethnographic approach, i.e., combining first-hand observations and conversations with active participation in people's ordinary activities over a long period of time (Fetterman, 2010). She conducted participant observation in approximately 30 ICT courses in AG, which she attended on a weekly basis. In 2011, she also set up a Facebook group, which, at the time of writing this paper, is still active, with 49 participants approximately $60 \%$ of them were also involved in the Life 2.0 activities. In 2014, she joined a WhatsApp group managed by 25 of them. These groups allowed her to keep in touch with some participants after class hours and beyond the duration of the projects.

In hindsight, these activities, which were conducted in parallel to the projects, helped us conduct the design and evaluation activities in both projects. For instance, while we were evaluating the prototypes developed in Life 2.0 and WorthPlay, our observations were guided by our previous knowledge of the ordinary behaviours of participants and dynamics in AG classes. In addition to ICT-focused activities, the first author participated in language courses as a learner. She also participated in the organization of dancing events, attended conferences organised in AG, and took part in cultural gatherings too. We argue that this active and longterm involvement in AG allowed us to understand the (lack of) adoption of the technologies developed in the projects, as well as the new activities and social dynamics created by the participants.

\subsection{Data gathering and analysis}

The first author took paper-based notes of her first-hand observations and conversations with the participants during or immediately after the ethnographic, PD and evaluation activities. She did not video- or audiorecorded any of them because this could have been a very intrusive practice, given that participants were not used to being recorded while taking part in courses in AG. Instead, note-taking was a common practice amongst all the participants. On some occasions, especially when she was heavily involved in an activity (e.g., talking with participants, running the activity, or answering questions), she had to rely on her memory and a narrative of the activity was therefore added to the notes, which she then transcribed in an MS Word document for analytic purposes.

While still collecting data, she conducted preliminary data analysis (approximately every 4-5 weeks) with the aim of identifying possible topics to follow them up. This preliminary analysis consisted in reading previous notes, highlighting repetitive patterns and identifying unclear issues by asking questions such as "what?", "why?", "what if?"

The entire data corpus was analysed, in a recursive and inductive way, by using the six-phases of thematic analysis (Braun \& Clarke, 2006). To begin with, she read all her notes (1) several times to familiarise herself with their contents, due to the long-term aspect of the study. She then generated initial $\operatorname{codes}^{8}(2)$, most of them by working at a latent level of the data (e.g., identifying and examining the underlying ideas beyond, for instance, participants' quotes). When all the initial data was coded, she identified themes by grouping related codes together (3). She then reviewed themes in an iterative mode (4), by moving and / or deleting codes and by checking for 'accurate representation' (Braun \& Clarke, 2006) of the entire data set. Themes were named (5) and preliminary versions of this paper were written (6), as writing in thematic analysis is considered an essential step of the analysis process, shared and discussed amongst all the authors of the paper.

As the writing and analysis progressed, our focus shifted towards the data coming from the evaluation and co-design phases ${ }^{9}$. This shift is accounted for (a) the analysis of the conceptualization phase, which yielded themes which had already emerged from the ethnographic study, and (b) our interest in aspects of the data concerned with the socio-cultural contexts of the design process, including designers' influences and assumptions, as these aspects helped us to explain the reasons for which the developed technology was (not) successfully being used. In this phase, the analysis started to shift from a realistic to a constructionist paradigm. We also progressively turned our attention to relevant literature related to critical theories of technologies design (e.g., postcolonial, feminist), which helped us to sensitize ourselves to more subtle

\footnotetext{
${ }^{8}$ A code is defined in this paper as a piece of text that, independent from its length (e.g., could be a sentence, words or paragraphs), captures the richness of a phenomenon (Boyatzis, 1998).

${ }^{9}$ The iterations that followed were therefore conducted mainly with the data gathered in the evaluation and co-design activities. We also went back to the entire corpus occasionally in order to check for consistency.
} 
features of the data (Tuckett, 2005 - cited in (Braun \& Clarke, 2006)), and to ground the dimensions of the proposed Turn (see Section 5).

The core themes that emerged from our analysis and that we use to present the results are:

- Conceptualization of the subjects of design: who needs help? Only for older people? For all older people?

- Conceptualization of the technology and its intended use: who needs help? Are co-designed technologies intrinsically meaningful?

\section{Triggers of the turn to community: selected findings}

In this section, we present a selection of the results of our study. These selected results are central to the turn to community discussed in Section 5. The results (i) show how the initial design concept theorised by researchers in both projects evolved over time as a result of the increasing appropriation of the technology in AG, (ii) address potentially taken-for-granted ideas about the way of conducting HCI research with older people that one can develop by analysing a large number of previous works, and (iii) reveal the role of community in providing a different way of thinking about and doing HCI research and design with older people. Table 1 provides an overview of the key findings.

\begin{tabular}{|c|c|c|c|c|}
\hline Finding & $\begin{array}{c}\text { HCI common } \\
\text { approach }\end{array}$ & $\begin{array}{l}\text { Our initial } \\
\text { assumption }\end{array}$ & Points of conflict & $\begin{array}{c}\text { Resolution } \\
\text { Evolved technology } \\
\text { meaning }\end{array}$ \\
\hline $\begin{array}{l}\text { Who needs } \\
\text { help? }\end{array}$ & $\begin{array}{l}\text { "HCI researchers have } \\
\text { largely been concerned } \\
\text { with the downside of } \\
\text { aging; focusing on } \\
\text { assistive technologies } \\
\text { that can help } \\
\text { compensate for people's } \\
\text { frailties and the } \\
\text { assumed needs that } \\
\text { arise when getting } \\
\text { older" (Rogers, 2014) }\end{array}$ & $\begin{array}{l}\text { Life } 2.0 \text { Older people } \\
\text { will use the Mutual } \\
\text { Help service to ask } \\
\text { for help for } \\
\text { conducting daily } \\
\text { living activities such } \\
\text { as doing their chores } \\
\text { and shopping. (Ph-2) }\end{array}$ & $\begin{array}{l}\text { Participants considered } \\
\text { that the Mutual Help } \\
\text { service that they had } \\
\text { helped to co-design was } \\
\text { aimed to other older } \\
\text { people. Consequently, } \\
\text { they did not appropriate } \\
\text { it. }(\mathrm{Ph}-2)\end{array}$ & $\begin{array}{l}\text { By situating the Mutual } \\
\text { Help service within the } \\
\text { context of the AG } \\
\text { community, the } \\
\text { meaning of 'help' } \\
\text { turned into sharing } \\
\text { knowledge, and the } \\
\text { service was therefore } \\
\text { appropriated. (Ph-2 \& } \\
\text { Ph-3) }\end{array}$ \\
\hline $\begin{array}{l}\text { Only for older } \\
\text { people? }\end{array}$ & $\begin{array}{l}\text { Much research attention } \\
\text { has been paid to the } \\
\text { design of technologies } \\
\text { that help older people } \\
\text { keep in touch with their } \\
\text { relatives (Vines, 2015) } \\
\text { and / or caregivers } \\
\text { (Rogers, 2013) }\end{array}$ & $\begin{array}{l}\text { Life } 2.0 \text { The } \\
\text { platform should be } \\
\text { targeted at older } \\
\text { people, their relatives } \\
\text { and caregivers, } \\
\text { because they are key } \\
\text { members of their } \\
\text { everyday social } \\
\text { network. (Ph-0) }\end{array}$ & $\begin{array}{l}\text { Participants, who were in } \\
\text { good health, were against } \\
\text { having caregivers } \\
\text { involved in the project. } \\
\text { Participants also refused } \\
\text { to have their family } \\
\text { members involved, } \\
\text { especially their children, } \\
\text { because they always told } \\
\text { them that they were very } \\
\text { busy. (Ph1) } \\
\text { Participants showed a } \\
\text { sense of unease with the } \\
\text { project being articulated } \\
\text { "only for older people". } \\
\text { (Ph-3) }\end{array}$ & $\begin{array}{l}\text { Participants considered } \\
\text { the platform to be a } \\
\text { technology that could be } \\
\text { used by the whole } \\
\text { neighbourhood. }(\mathrm{Ph}-3)\end{array}$ \\
\hline $\begin{array}{l}\text { For all older } \\
\text { people? }\end{array}$ & $\begin{array}{l}\text { The HCI community } \\
\text { has often portrayed } \\
\text { older people as an } \\
\text { homogeneous group } \\
\text { and attempted "to } \\
\text { develop technologies }\end{array}$ & $\begin{array}{l}\text { Worthplay We } \\
\text { aimed to design a set } \\
\text { of meaningful games } \\
\text { for "older people", } \\
\text { drawing upon the } \\
\text { assumption that all }\end{array}$ & $\begin{array}{l}\text { Participants had different } \\
\text { attitudes towards digital } \\
\text { games. Participants also } \\
\text { had different likes and } \\
\text { interests (e.g., music, } \\
\text { literature, geography). It }\end{array}$ & $\begin{array}{l}\text { We built an online } \\
\text { platform that enables } \\
\text { the participants to create } \\
\text { their own games in } \\
\text { order to account for } \\
\text { their diversity of }\end{array}$ \\
\hline
\end{tabular}




\begin{tabular}{|c|c|c|c|c|}
\hline & $\begin{array}{l}\text { that respond to } \\
\text { generalised insights } \\
\text { about the skills and } \\
\text { capabilities of a specific } \\
\text { cohort" (Vines, 2015) }\end{array}$ & $\begin{array}{l}\text { older people would be } \\
\text { willing to play a } \\
\text { particular game. (Ph- } \\
\text { 0) }\end{array}$ & $\begin{array}{l}\text { was therefore difficult to } \\
\text { define a single game that } \\
\text { could be considered } \\
\text { meaningful by all of } \\
\text { them. (Ph-1) }\end{array}$ & interests. (Ph-2) \\
\hline $\begin{array}{l}\text { Are co- } \\
\text { designed } \\
\text { technologies } \\
\text { always } \\
\text { meaningful? }\end{array}$ & $\begin{array}{l}\text { "The view of } \\
\text { technological potentials } \\
\text { is restricted and limited } \\
\text { to the stabilization of its } \\
\text { functionality without } \\
\text { discussing the ways of } \\
\text { appropriation of } \\
\text { technological devices } \\
\text { beyond the modalities } \\
\text { proposed during the } \\
\text { design phase" } \\
\text { (Rodeschini, 2011) }\end{array}$ & $\begin{array}{l}\text { Worthplay The game } \\
\text { platform will be } \\
\text { meaningful for the } \\
\text { AG community } \\
\text { because it was } \\
\text { designed with them. } \\
\text { Consequently, the } \\
\text { platform addresses } \\
\text { their interests and } \\
\text { needs. (Ph-3) }\end{array}$ & $\begin{array}{l}\text { The gaming platform } \\
\text { turned out not to be } \\
\text { meaningful for some } \\
\text { community groups to use. } \\
\text { These groups used the } \\
\text { platform just to try a new } \\
\text { technology out. In other } \\
\text { words, they had no } \\
\text { intention of incorporating } \\
\text { the platform in their } \\
\text { everyday practices. (Ph- } \\
\text { 3) }\end{array}$ & $\begin{array}{l}\text { The gaming platform } \\
\text { was only meaningful for } \\
\text { those groups that were } \\
\text { active in finding a way } \\
\text { of using it in their } \\
\text { practices. The gaming } \\
\text { platform acquired } \\
\text { different meanings for } \\
\text { different groups. (Ph-3) }\end{array}$ \\
\hline
\end{tabular}

Ph-0: project proposal; Ph-1: analysis - ethnography; Ph-2: Conceptualization - co-design; Ph-3: Evaluation

Table 1. Overview of key findings.

\subsection{Who needs help?}

Within HCI research with older people, one of the most dominant discourses is that of the 'rhetoric of compassion' (Rogers and Marsden, 2013), i.e., design technologies that help older adults do something. This discourse is consistent with (and can arguably be accounted for) the type of research and approach (e.g., assistive technologies) funded by ICT \& Ageing programmes (Vines et al., 2015). The Mutual Help service envisioned in Life 2.0 was no exception: it was expected to help older people to carry out daily living activities. However, prompted by the results of the ethnographic study, which highlighted a strong peer-topeer support among our participants, we attempted to go one step forward. We considered that the Mutual Help service could promote a more positive image of older people: not only are they in need of help but also capable of helping others. This vision was strongly supported by our participants, who considered that this service was a good thing. However, we assumed that the type of help that older people would be willing to share was related to conducting functional activities of daily life. This vision, which is aligned with the aforementioned 'rhetoric of compassion', transpired from the way we talked about the design idea in the sessions with our participants. For instance, a typical scenario that was used to describe the idea to our participants was the case of a woman/man who would like to be accompanied to the doctor, or that of a woman/man who asks a friend to go to the local supermarket to buy a bottle of milk for her/him.

During co-design activities our participants actively contributed to define several aspects of the Mutual Help service. They proposed alternative scenarios as well. For instance, we deeply discussed what mechanisms could be created to ensure trust among help exchangers, what actor/s in their local community could act as guarantor/s, what functionalities the platform should support and how it should look like.

Their active involvement and positive comments led us to believe that the service we were co-designing would be very useful and of great benefit to our participants. However, when we encouraged them to start using the first prototype of the service, we realized that they did not see themselves as the main target of the Mutual Help service. By revisiting our fieldnotes, we realized that in the co-design activities they were envisioning 'help' situations for 'other' people. In fact, most participants' comments were formulated in the third person: "This is, for example, for someone who wants to go to the doctor with another person", "Imagine someone who needs to change the light bulb and can't do it on her own. She can post a message on the platform and eventually get help from some of us". Over the course of the weekly meetings, during the design-in-use phase, it became evident that our participants were not willing to use what they contributed to co-design: "Perhaps we'll use the service when we grow older, but not now", "I don't know what I can offer. I don't know what I can ask for. I don't need anything. I don't have ideas..." 
Our participant's opinions resonate with those voiced by others, such as "not for me" (Neven, 2010) or "not that old" (Lund \& Engelsrud, 2008). While there are older people who are actually in need of help, and we consider that helping them is to be commended, our results indicate that the problem Life 2.0 sought to address was built on a conceptualization of the "intended older people" that did not match our participants" self-identity and that was oversimplified - perhaps, it is wrong to assume that all older people need help because they are 60 and above.

It could be argued that we could have attempted to recruit more participants in an attempt to look for older people who could be more into the initial idea of the service. However, doing so was, in our opinion, neither reasonable nor ethical. Ninety people (aged 60-80) with very different profiles (volunteers, living alone or with a dependent partner, interested and uninterested in ICT) were already involved in the study.

The fundamental problem was that we were attempting to design a decontextualized technology for a generic group of older people. Despite the chronological age of our participants, in our study, they primarily acted as active members of the AG community. Within this learning community, learning, and not age, was what characterized the group of participants. In fact, the Mutual Help service only started to be used when we understood help as knowledge exchange. Participants started to use the Mutual Help service to ask questions about, for instance, how they could use their smartphones or set up a Facebook account.

This result shows how important it is to situate "older people" within the communities in which they act in their daily life in order to better understand their identities and address them in the design process. At the beginning of our design activities, however, we started with the assumption that "older people" is a large user group, disconnected from other groups or communities, and that their needs and characteristics can and must be identified and addressed in the design process.

\subsection{Only for older people?}

Much research attention in HCI has been paid to the design of Computer-Mediated Communication technologies that enable older people to keep in touch with members of their social networks (mostly relatives and caregivers), and vice versa. In keeping with this approach, Life 2.0 was designed to target older people (aged 65-75), members of their families and caregivers. Yet, the idea of having relatives and caregivers involved in the project was strongly and unambiguously rejected by our participants. They associated caregivers with having serious impairments. However, they reported (and our observations confirmed) that they were fit for their age, and this was part of their identity: active and healthy older people. With respect to family members, they insisted on the fact that "our children are always very busy, better not to bother them with these things". We therefore decided to disregard the idea of involving caregivers and relatives in the project.

Does it mean that our participants wanted an online service only for themselves? Our participants were uneasy about the project being articulated only "for older people". During the evaluation and design-in-use phase, in informal conversations, presentations, and in dissemination brochures, we presented Life 2.0 as it was described in the project proposal: for older people. Participants pointed out that they saw the Mutual Help as a local community service where the age of the subscribers was not very important: "Why do you keep saying that this project is for older people? This could be for the entire neighbourhood! Everyone could need help! Didn't you ask our help to organize your trip to Menorca?" (to the first author) or "Young people now rarely know how to fix anything at home. We can help them because we know how to fix things at home!"

Our participants' conceptualization of the service clashed with the initial vision of the project, and, at the same time, reinforced a vision of older people in HCI that has yet to receive further research attention: older people as "socially proactive and autonomous - individuals [...] engaging in regular social activities with others -" (Vines et al., 2015, p. 12).

\subsection{For all older people?}

According to a review of 30 years of ageing research published across the SIGCHI community (Vines et al., 2015), the discourse of homogeneity predominates within this field, i.e., "it was notable how relatively few papers explored the heterogeneity of our ageing population" (p. 13). The discourse of homogeneity leads to developing "technologies that respond to generalised insights about the skills and capabilities of a specific 
cohort" (ibid, p.19). This discourse dominated the proposal of the WorthPlay project, whose initial goal was to design several games for older people. The project drew upon the assumption that older people would be willing to play a particular game. However, the initial 3 months of ethnographic research presented a remarkably different picture. Some participants were really into playing games, while others regarded this activity as a waste of time or as a childish activity (Sayago et al., 2016). We took this heterogeneity as an opportunity to change our conceptualization of older people and the gaming technology. A single game, or a set of few games, was very unlikely to cater for this heterogeneity. Thus, we decided to design an online Game Creation Platform, hoping to meet their diverse interests. In doing so, we changed our own way of thinking about older people: from players to both players and creators of games.

Most of the games created by the participants were knowledge games. This might not be surprising, as these games resonate with their shared motivation and the context (a learning community). The knowledge exchanged was very diverse and related to their interests and previous jobs, ranging from geography and arts to mathematics and personal memories. This diversity can be taken as a sign of the differences in interests and heterogeneity of the life course. The different ways in which the platform was used for, e.g., making geo-enabled literature routes or brushing up on the contents learned during an Internet course, is another evidence of the diversity we found: different groups of older people ascribe different meanings to the technology. This heterogeneity is consistent with findings discussed in several areas, such as ageing studies (e.g., Hofer and Alwin, 2008), psychology of ageing (Schaie and Willis, 2011) and social gerontology (Bond et al., 2007), wherein ageing is widely regarded as a highly heterogeneous and multifaceted process.

\subsection{Are co-designed technologies always meaningful?}

By reviewing the approaches adopted in studies concerned with the relationship between ICTs and older people, (Rodeschini, 2011) pointed out that "although the studies presented emphasize the user's role, elderly people are considered as receptors of a predesigned, specific technology, and not as an active part of a process" (p. 527). She pointed out that many studies restrict their focus on the stabilization of the functionalities of the technology, or the evaluation of their usability and acceptability, "without discussing the ways of appropriation of technological devices beyond the modalities proposed during the design phase" (p.527). In keeping with this view, the results of the evaluation activities conducted in WorthPlay stress the importance of promoting appropriation in order to understand the real meaning that users ascribe to technologies and going beyond the vision proposed during the design phase. The results also show that, even though participants contributed to co-design the technology, this does not mean that the technological product is intrinsically meaningful for them.

The WorthPlay platform was evaluated in different contexts during ordinary activities in AG, such as a course on general knowledge (GK), a book-reading club (BC) and two courses on computers and the Internet (CI). The evaluation activities were conducted in playing sessions, wherein the participants were encouraged to use the WorthPlay platform to play an existing game and to create a new one. Approximately 30 games were created. This number of games can be regarded as a success. Yet, participants showed different interests in using the platform. Also, they did not use them in the same way.

Although both GK and CI participants valued positively their experience of playing and creating games, our observations revealed different levels of engagement. CI participants often complained about having to answer another question or writing the answers when they had already done so verbally. Seldom did participants discuss the answers with other participants in the group, contrary to the typical behaviour exhibited by the same participants in regular class sessions. Despite the fact that $80 \%$ of the participants reported that they had enjoyed the new activity and had learned new things, the overall picture was not so positive. Indeed, the activity was unambiguously perceived as extraordinary and not useful, as illustrated by the following comment by a participant "If there's no regular class today, then I'll leave... with your permission. I have other things to do..."

In the GK group, however, we observed shouts of joy when participants answered correctly a question. We also observed how different playing groups yelled at each other - expressions of healthy competition. The participants reported that they had enjoyed the activity a lot. They also pointed out that this activity was a funny and useful way to brush up on contents learned over the academic year while familiarizing themselves with technologies they do not normally use. They enthusiastically discussed with the teacher of the group the 
possibility of repeating the activity in following editions of the course. Two of them repeatedly asked us if they could play the game at home. No participant in the CI class raised this question.

The case of $\mathrm{BC}$ is another example that shows how the same technology could be used in different ways. $\mathrm{BC}$ participants meet weekly in Àgora to read and discuss books. When we proposed them to use the WorthPlay platform, some of them were reluctant to do it: "this class is about reading books, not using technologies!" However, and thanks to some very motivated participants, the group finally decided to use the platform as a way to further discuss and discover aspects of the book they were reading. They did so by creating a route of questions, which were geo-located in specific points of the city centre, and answering them in situ through the use of iPads. The answers given by the different players stimulated discussions about the book. The activity, which was rated highly positively by all the participants, triggered a new practice that is still being conducted within the group: literature routes around the city (see Righi et al. 2015).

The difference in technology acceptance in the three groups seems to lie in the degree to which the groups engaged in the organization of the activity. There was a strong involvement of the teacher ${ }^{10}$ in the GK class, who prepared the game to be played ensuring the relationship with the course contents. The teacher also introduced the activity to the participants and helped them to answer the game questions. The teachers in the CI class were less participative. Yet, they allowed us to organize and carry out the activity by our own. BC participants stated very clearly that they would use the platform only if it helped them achieve their goals, and they showed a proactive attitude in finding the proper way to use it within their current practices.

These results show that the co-designed technology became relevant only in those situations where users actively appropriated it. Appropriation occurred when a dialogue between the opportunities that technology presents and existing practices was established. The results of the appropriation were new practices and an enriched technology that acquired different meanings in different contexts. For instance, in GK, the platform was conceived of as a playful tool for brushing up on the contents of the course, while in BC, the platform was used as a way to enrich their discussion about books. In CI, by contrast, appropriation did not take place; the platform was perceived as a technology to be tried out, but people could not make the most out of it. Moreover, it is worth noting that participants of $\mathrm{BC}$ did not consider the Worthplay platform to be a digital game.

\section{The "Turn to Community" in HCI design for, and with, older people}

This section elaborates on the findings presented in section 4 by discussing them along with previous studies and theoretical frameworks. The results of our study prompted us to introduce a different perspective, which we label 'turn to community', on HCI design and research conducted with, or concerned about, older people. We think of the turn to community as a lens through which we can re-conceptualize both the subject and the object of design activities. Figure 1 summarizes the main implications of adopting this new perspective.

\section{TURN TO COMMUNITY}
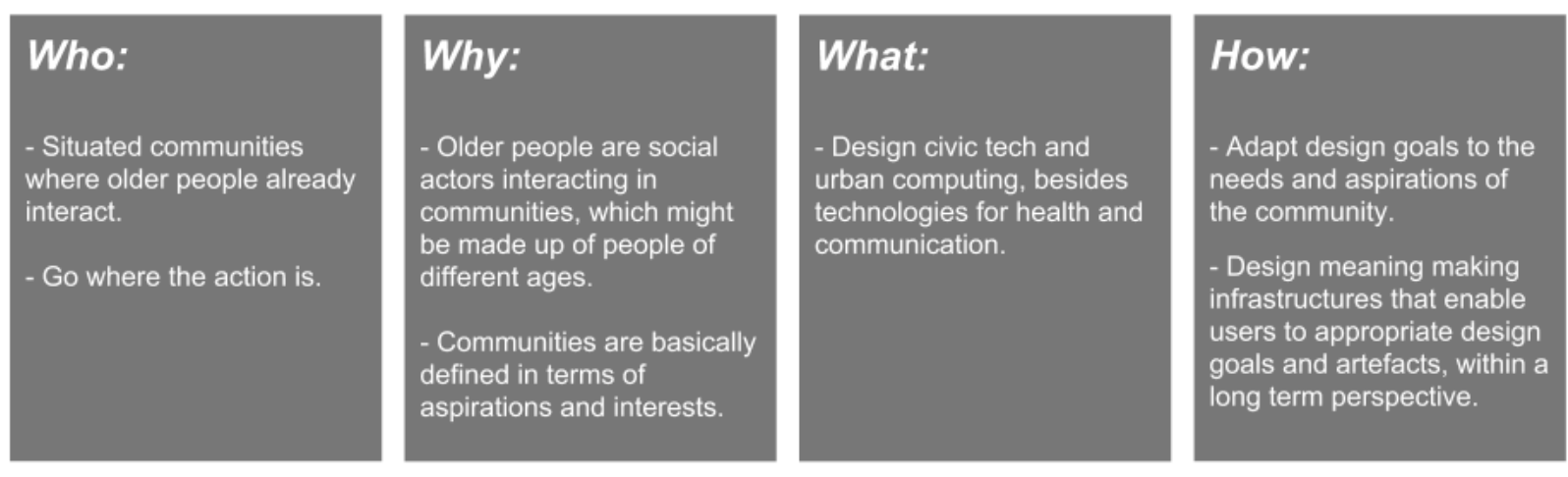

Figure 1. Overview of the Turn to Community

\footnotetext{
${ }^{10}$ In Àgora, teachers are volunteers who coordinate the class by suggesting content and helping out participants. The contents of the class are mostly decided by the participants based on their interests.
} 


\subsection{Re-thinking the subject of design: from older people to situated communities}

The findings presented in 4.2 and 4.3 showed that the assumptions on which our design choices were based rested upon a taken-for-granted idea: our design is targeted at a specific category of end-users, i.e., older people. This turned out to be problematic for two main reasons. Firstly, by aiming at a specific group of people, we were indirectly suggesting that they "share some common set of abilities, orientations and requirements" (Gaver et al., 2010, p.2056), which (should) enable designers to propose a technology that is supposed to be meaningful and useful for the entire group. This implied homogeneity clashed with the great variety of older people's life experiences, interests and abilities, which is fairly well-documented in previous research (see section 2) and in our results too (section 4.3). Secondly, 'design for older people' might lead us to believe that older people are a user group that can or should be set apart from others. However, our findings, especially those related to the Mutual Help service (section 4.2), suggest that this separation might not always be clear, useful or necessary.

These findings add weight to concerns about the tendency of HCI studies to create manageable categories of users, such as young, older people and visitors, and to think of them as homogenous user groups (e.g. Kukka et al. 2014; Dourish and Mainwaring 2012). By bearing these general categories in mind, designers are tempted to think that they create technologies for everybody. However, these technologies are actually designed for an "anonymous composite person made up of a number of people falling into a given demographic category" (Kukka et al., 2014), under-representing the diversity of social practices, interests and skills (Williams et al., 2009). Similar claims have been made in HCI4D. For instance, (Marsden et al., 2008) questioned cultural "averages" for being of limited use for design, and (Irani et al., 2010) took issue with the tendency to design for static, nationally-bound cultures, proposing instead to adopt a generative view of culture and design in conversation with existing cultural practices.

How do designers come up with these categories of users? HCI scholars have drawn upon post-colonial and feminist theories to explore how identities are created in social and cultural contexts, how relations of power affect the construction of such identities, and how these constructions influence the design of technologies. Most of these analyses come from cross-cultural design projects conducted with indigenous or marginalized groups. These projects are often framed from the perspective of the outsider / western researcher who looks 'out there' from 'in here' (Taylor, 2011). This perspective clearly does not fit in well with the specific cultural context where the technologies are supposed to be used (Dodson et al., 2012; Kapuire et al., 2015; Marsden et al., 2008; Cabrero et al., 2016). In a similar vein, feminist theorists criticize the universality presented and claimed by dominant groups (Haraway, 1988), and question what constitutes "valid information", inviting to go beyond taken-for-granted assumptions in the design for technologies (Bardzell \&Bardzell, 2011).

To overcome the "universalizing schema that typify the research 'out there" (Bidwell et al., 2013 p. 31), some researchers propose to adopt a situated lens on technology design (Dourish \& Mainwaring, 2012). This lens encourages designers to acknowledge the specificities of the place in which design is carried out, not only in terms of physical aspects, but also in terms of institutional, cultural, commercial and historical circumstances (Suchman, 2011). Moreover, it is claimed that a situated lens on design contributes to shed light on the mechanisms by which knowledge about the design subject is produced, including designers' assumptions (Harrison et al., 2011; Haraway, 1988).

We consider that similar reflections can be made in the field of HCI research with older people, wherein these issues have yet to be examined more critically. By framing the research and design as "for older people", most designers engage in a process of "othering" designer set-up as a user group that is clearly separated and different from the rest of the population. This pre-defined, decontextualized and separated demographic category becomes the main subject of design. A remarkable example that shows the weaknesses of this approach is the study conducted by Gaver et al (2010), in which they designed a prayer companion for a community of nuns. The peculiarity of that community - i.e., most of the members were in their 80 s and lived a very atypical life due to their religious vows - forced the researchers to challenge the view of "'older people' as a category of people who, by

\footnotetext{
${ }^{11}$ Post-colonial theorists adopted the term "othering" to indicate the process by which individual or groups are set aside as different.
} 
implication, share some common set of abilities, orientations and requirements" (Gaver et al., 2010, p. 2056). Some of our results, especially those highlighting the inapplicability of a unifying concept of 'help' (section 4.1) or a single game for all older people (section 4.3) reinforce the need of this challenging.

How can we adopt a situated lens when designing technologies for older people? It could be argued that several HCI design methods already adopt a situated lens because they highlight the importance of the context and provide us with tools to examine it. Examples are Contextual Design (Holtzblatt and Beyer, 2014) and some forms of ethnography applied to design (Crabtree et al., 2000). These approaches mainly focus on helping us understand individuals' activities where they occur. While these approaches have proven to be useful to understand and design a wide range of people's activities and technologies (e.g. Chiou et al., 2014), the problem we see is how to define the context/s and activities that characterize broad social categories of users, such as older people, immigrants, teenagers. What we might end up designing, for, say, an older person that belongs to a community of dancers by conducting Contextual Design or ethnographically-inspired design methods, might not necessary be meaningful to an older person who is part of a community of reader enthusiasts. Despite the fact that they are both associated to the same social category, they interact in (very) different communities.

Our turn to community aims to address this problem by encouraging HCI researchers and designers to (i) detach the subjects of design (older people) from any predefined category and (ii) acknowledge the situated validity of the knowledge produced in a specific context. A turn to community does not position itself as a new paradigm, design or research method. Nor is it aimed to replace Contextual Design or ethnography. Indeed, we drew heavily on them in our research-through-design study. We see our turn to community as a research and design mindset that encourages design researchers to position "the institutionalized ways of knowing" (Jasanoff 2004) in a specific context. As Dourish (2004) states “context isn't just 'there', (...) [context] is actively produced, maintained and enacted in the course of the activity at hand" (p.22). We consider that everyday communities provide us with a practical way to enact contexts. As in the coproduction theory of science and technologies studies, the turn to community invites to question the formation and maintenance of the identities (Jasanoff, 2004), inviting designers to consider the role played by situated communities in constructing what it is known to mean "older people" within a specific design project.

Three implications can be drawn from this changed mindset.

\section{a) Think of older people as social actors and widen the possible design spaces}

We consider that a turn to community encourages us to think of older people as social actors interacting in different social groups / communities, which are embedded in everyday contexts and civic life. This view departs considerably from the most traditional one, which sees older people as isolated and passive individuals in need of help. While most HCI studies have focused on developing technologies to support older people's communication and activities in relation with their family members or caregivers, by thinking of older people as social actors, we can widen this design space, which seems to be reduced to intergenerational communication and health. A turn to community invites us to have older people engaged in design activities conducted for and within civic contexts, such as neighbourhoods and local community groups. This means, for instance, examining the role of older people (together with other age groups) when exploring urban computing, social activism, and civic tech, areas to which the HCI community is paying increasing attention (e.g. Boehner and DiSalvo, 2016; Balestrini et al., 2017).

\section{b) Do not recruit older people for your study, go where the action is}

Since we regard older people as social actors, the turn to community encourages designers to go 'where the action is' (Dourish, 2001) - in particular, in the communities where they dynamically and contingently act in their everyday life. This approach is in stark contrast to setting up a user group with people of a certain age, and who probably do not know each other. While other researchers have claimed that older people can be considered a community of identity, seeing age as a common identity (DiSalvo et al., 2013), we argue that everyday communities can be made up of people of different ages who share a common interest. In fact, the driving force in the design process is a given practice, issue or interest, rather than preconceived identifiers associated to social categories. 
It is worth noting that this implication might not be suitable for designing studies that, because of their nature, must be conducted under very controlled situations and recruit subjects according to certain and strict parameters (age range, cognitive abilities...).

\section{c) Think across ages}

The boundaries between age groups might not be evident in (some) everyday communities. This should encourage designers to question the extent to which the design solutions created in studies targeted at older people can be considered valid for different age groups. In other words, the turn to community invites us to adopt an age-inclusive approach, rather than an age-segregated one. One might be tempted to relate this approach with Universal Design, Inclusive Design, or Design for All. Common to all of them is to design products by taking into account the needs of an extensive spectrum of the population in order to ensure that mainstream technologies can be used by as many users as possible (Persson et al., 2014). As opposed to the turn to the community, which focuses on people shared interests, goals and practices, these design approaches concentrate strongly on the user's functional abilities. Thus, although we share the ultimate goal of building a more inclusive (digital) society, the way to reach this goal is different - but not mutually exclusive.

\subsection{Re-shaping the object of design: from digital artefacts to meaning-making infrastructures}

In section 2.1 we gave examples of how the way in which designers conceptualize older people in previous studies (e.g., passive vs. active) influence the design space (e.g., assistive technologies vs. technologies that build upon people's ingenuity). How does the lens on community change the way to look at the technology to be developed, i.e., the object of design? To answer this question, we analyse briefly the way in which the object of design has been considered in HCI studies with older people thus far.

User-Centred Design (UCD) has been widely adopted in the HCI community. Central to the UCD approach is to have end-users involved ${ }^{12}$ in the design process in order to adjust products to people, rather than forcing them to adapt to the product by changing their behaviours. Within this approach, the technology has to be fine-tuned so that it fits well into user's existing practices. To achieve this goal, the design process starts by gathering user's needs by means of, for instance, contextual interviews, ethnographical observations and focus groups. The designer therefore creates a list of fairly well-defined requirements and translate them into a design concept aimed to meet the users' needs.

UCD has played a pivotal role in building more useful, usable and effective digital technologies. However, some limitations have been identified, e.g., "Trying to optimise fit on basis of knowledge about use and users, we risk trapping people in a situation where the use of our designs has been over-determined and where there is not enough space left to act and improvise." (Redström, 2006, p. 123). Similar concerns have been translated in the field of technology design for older people by Peine et al. (2014), who claimed that "Older people are assumed to follow what designers offer to them, and it is therefore the tasks of designers to understand and meet the needs of older persons. This involves an uncomfortable framing of older technology users as passive recipients of technologies [...] that have to be comforted rather than challenged by new technology" (p. 204). Although we may be tempted to "emphasize user's role" [in the co-design of the artefact], "elderly people are considered as receptors of a predesigned, specific technology" [thus giving] "the users a passive role, because they do not affect the technological artifact and its concrete modes of use in any way." (Rodeschini, 2011, p.527). Within this approach, the object of design is the stabilization of the digital artefact.

As pointed out by (Rodeschini, 2011), the involvement of users in the design process remains incomplete if we do not discuss the ways in which technological artefacts are appropriated and reshaped beyond the visions proposed during the co-design phase. In fact, the use envisioned in co-design activities "is hardly the same as actual use, no matter how much participation there has been in the design process" (Ehn, 2008, p.95). Our findings support the importance of looking at appropriation in order to fully understand what new meanings older people attach to technologies when they incorporate them in their daily practices. In section 4.1 we showed how the Mutual Help service was transformed into a sharing knowledge service when it was used by a specific group of participants, who were more interested in learning than in receiving support to

\footnotetext{
${ }^{12}$ User involvement has taken different forms, ranging from involving users mainly as informants of their routine and needs, to involving them as co-designers, partners and drivers of the design process.
} 
conduct daily activities. Section 4.4 showed how different groups of older people used the Worthplay Games Creation Platform for different purposes and activities, which were not always related to games, despite our original idea. Both findings are exemplary of the active role of communities in changing the 'imposed' meaning of technologies, and overcoming assumptions.

In order to support this active role, we consider that when designing technologies for older people, we should widen the object of design, moving from merely designing a digital artefact, which is the most common design approach in HCI with older people, to also designing a meaning-making infrastructure, i.e., a set of activities aimed to foster appropriation and encourage people to re-shape the use envisioned in the design phase. Two implications can be drawn from adopting this perspective:

\section{d) Adapt the envisioned technologies to community goals to overcome taken for granted assumptions}

Embracing a meaning-making approach means that researchers acknowledge that the original idea written in the research proposal might not be the one that gets finally implemented. Instead, we encourage designers to allow communities to define the design space rather than imposing their design end-goals on them. We consider that this can help us to avoid taking universal needs associated to older people for granted. As a consequence of the meaning-making approach, researchers should be prepared to change the way they talk about the design solution by embracing the perspective (and the language) of the participants.

\section{e) Working with community forces us to adopt a long-term lens in the design process}

Community should not simply be seen as a new setting for conducting evaluations in out-of-laboratory conditions. Dropping a new technology in a community would not necessarily make a digital artefact more engaging and useful (see section 4.4). On the contrary, the importance of understanding community (and technologies) in long-term studies in order to explore and understand how the meaning of technologies unfolds over time, allowing uses that go beyond the ones envisioned in the design phase, stands out in this paper. Long-term studies of ICT use are rare within HCI research with older people, however. Noteworthy exemptions are (Sayago and Blat, 2010; Botero and Hyysalo, 2013).

\section{Discussion}

This section aims to discuss the extent to which the perspective introduced in this paper takes one step forward HCI research and design with older people by incorporating, altering and keeping pace with theoretical advances in the field.

\subsection{Relationship with other turns in HCI}

HCI has experienced a number of paradigm changes (Harrison et al, 2007), which are often referred to as 'turns to' or waves (Bødker, 2006). Rogers (2012), for instance, discusses four major turns that are worth considering for the purposes of this paper: turn to design, turn to culture, turn to the wild and turn to embodiment.

The turn to design as a theoretical concern invites interaction designers to think about design not only as a set of steps to be followed in order to create a user interface but also as a way of designing for lifestyles. Concepts such as positive computing (Calvo and Peters, 2014) and user experience (Hassenzahl, 2010; Wright and McCarthy, 2010), which attempts to go beyond the instrumental (e.g., conducting tasks) and designing for preventing frustration and errors (Hassenzahl and Tractinsky, 2006), have gained momentum. The turn to culture highlights the fact that "many of our concerns about human nature and conduct are about interpretation" and this means that people's everyday practices should be understood from a number of different perspectives. The turn to the wild focuses on "how pervasive technologies can be designed to enhance and become part of the everydayness of life" (p. 73). The turn to embodiment is prompted by the seminal "Where the Action Is" (Dourish 2001) and about understanding interaction in terms of practical engagement with the social and physical environment. It is also acknowledged that there are other turns, such as the turn to practice, which "examines historical processes and performances, longer-term actions which persist over time, and that are situated in time and space, and are dependent on many features of the surrounding material and cultural environment" (Kuuti and Bannon, 2014, p. 3543). Central to this turn are practices, which do not occur in a vacuum. Instead, practices are defined as "a shared resource amongst a community of people" (p, 3550). 
Although the perspective (turn to community) introduced in this paper cannot be compared to the aforementioned major turns (or changes of paradigm) in HCI research, because these characterize well consolidated HCI theories, it shares a number of elements with them. Our turn to community aims to encourage HCI researchers and designers working with older people (and, perhaps, other user groups) to rethink the object and subject of design, going beyond the digital artefact per se. To do so, the researcher should get him or herself immersed in a community so as to understand its values, goals, interests, and everyday practices. This immersion is a key aspect of the turn to culture, the wild, and embodiment.

With respect to the turn to practice, central to it, and to our turn to community, is to "decenter (this) privileged position of interaction, and to consider (this) human-machine interaction as only one factor among several that are interesting and important" (Kuutti and Bannon, 2014, p.3544). In our case, "the position of interaction" refers to the predominance of the compensation model within HCI and older people. This might be counterintuitive, given that older people should be at the centre of design activities targeted at them, and our turn to community emerged from R\&D aimed at older people. Yet, if the design (and research) activities focus too much on them, they fail to appreciate other aspects (social practices, motivations...) that determine to a large extent their relationship with existing and yet-to-be designed technologies. Both turns also aim to "give us a variety of conceptual resources to understand important issues of appropriation and assimilation of technology into everyday life" (ibid, 3550). In particular, our turn to community highlights three conceptual resources, which are, to the best of our knowledge, not addressed in either the turn to practice or any of the others. In addition to making more specific the context where to find practices (communities), our turn to community encourages designers and researchers to move from designing for older people to designing for the community / communities they belong to, and from designing a digital artefact to designing mutually-shaping relationships between technologies and everyday practices.

\subsection{Relationship with theories of appropriation in $\mathrm{HCI}$}

The turn to community encourages us to look at the way in which older people adopt and shape the meaning of technology while using / appropriating it in communities. We acknowledge that appropriation has often been explored in previous HCI studies (e.g. Storni, 2010; Salovaara et al., 2011; Bødker and Christiansen, 2012). Appropriation takes time and these studies tend to be conducted over long periods of time. We also admit that claiming that the meaning of technologies is situated is not new, as it is well-known in other areas related to HCI and amongst HCI scholars (e.g. Dourish, 2001, Suchman, 1987). Yet, we contend that these concepts have seldom been considered in HCI studies with older people, because most of them are either conducted in laboratory conditions or during a period of time which makes it difficult to study technology appropriation (Sayago et al., 2011). We argue that a focus on appropriation could encourage HCI research to move away from technology genericity and acknowledge instead the different ways in which older people ascribe different and evolving meanings to technologies.

\subsection{Relationship with other approaches for designing for ageing}

We argue that the turn to community is a point of departure from the most widespread design approaches for older people within HCI, which fall broadly into three main types: i) focusing almost exclusively on agerelated changes in functional abilities, which is typical of and inherited from Human Factors / Ergonomics (Fisk et al., 2009), ii) considering older people's social relationships (mostly relatives and caregivers) and practices of ICT use, such as intergenerational play and communication (Vetere et al., 2009; Cornejo et al., 2013), and iii) going beyond the previous two to explore other aspects closer to the third wave HCI research, such as creativity (Rogers et al., 2014). Common to all of them is the fact that older people are at the centre of the research. Adopting a turn to community, however, requires us to 'decenter' this position of older people and to explore the community to which they belong. This does not mean that their individual abilities and social relationships should not be explored. Rather, a turn to community encourages us to reframe research questions by replacing "for older people" with "their community". This re-framing might also be valid for HCI studies conducted with other users groups. Future studies will confirm or reject this idea.

\subsection{Relationship with new meanings of design in HCI}

HCI has traditionally focused on the technological artefact. However, the HCI approach to design has evolved over time and its current focus is now wider than it was before (Bannon and Ehn, 2012). Participatory Design, Science and Technologies Studies have challenged the focus on artefact and its 
functionalities. Design is no longer about giving form to material/digital objects and defining how to interact with them. Design is becoming more and more about staging encounters between human and non-humans where matters of concern can be dealt with (Ehn, 2008). Infrastructuring (e.g. Karasti and Syrjänen, 2004; Ehn, 2008; Bjögvinsson et al., 2012), which is about building fertile ground to sustain participation of publics (Le Dantec and DiSalvo, 2013) over long periods of time and allowing new opportunities to emerge and reveal dilemmas and controversies, is the term used by design researchers to refer to this process. Longterm commitment and open-ended design are key aspects of infrastructuring (Marttila and Botero, 2013). The turn to community, with its focus on long time frame and meaning-making, supports these design trends in HCI. To the best of our knowledge, it also introduces them in the field of HCI research with older people. Our study has also showed how embracing these new perspectives can help us to overcome assumptions and become aware that participatory design processes alone do not ensure technology adoption. We consider that these results call for a deeper examination within HCI community about failures and limitations of (some) participatory processes, and for a critical reflection on the rhetoric of empowerment that often goes with involving users in design.

\subsection{About the range of applicability of the turn to community}

There is room for wondering whether a turn to community can be adopted if a community does not (seem to) exist. In fact, designing when a community does not exist is an open challenge in Participatory Design (Binder et al., 2012). However, it is well known that humans need to belong, despite the fact that the communities might not stand out. We build upon this fact and argue that a community lens should, first of all, be regarded as a way to shed light on how people construct their own identities within socio-cultural contexts. We postulate for leveraging on such identities during the design process. One might have few social interactions. Still, that person has a need to belong to a group, have some relationships, and might probably have interests or issues in common with others. Designers could leverage on these interests to drive the design process, and perhaps build a community around such a shared interest / issue. An artful work of infrastructuring might be needed to align actors around the shared concern (DiSalvo et al., 2013).

We also consider worthwhile to reflect on the fact that the research-through-design study that prompted us to formulate the turn to community was conducted mainly within a specific context (e.g., educational centre) and with a particular profile of older people (e.g. socially active). We recognize that this could be regarded as either a limitation or an attempt to neglect the role of design research to address more vulnerable profiles of older people. There is also room for thinking how specific the turn to community is with respect to older people, given that central to this turn is the term community (and not the social category of 'older people').

We consider that the turn to community positions itself primarily within the evolving transformation experiencing in HCI with older people, which we have described in 2.1.2 and 6.2. In other words, HCI researchers are increasingly looking at positive aspects of ageing, creative design scenarios and adopting more participatory approaches. The turn to community makes one step forward by inviting researchers to eradicate the subject of design from the implicit social category of older people and embrace a more inclusive lens that consider older people seamlessly embedded in civic contexts. Nevertheless, this inclusive approach should not make us overlook the challenges faced by society in providing care to dependent older people who find it hard to engage in civic life. We invite researchers focusing on other design goals and profiles of older people (e.g., assistive technologies for frail people), and working with other users, to adopt a turn to community. By doing so, we believe that this future research can enrich the turn to community by adding to it new dimensions and challenges that are difficult to address in a single paper and that we may therefore have overlooked.

\section{Conclusion}

In this paper, we have presented a 5-year research-through-design study, wherein we conducted ethnographic, design and evaluation activities in two R\&D projects aimed to design digital technologies that promote positive images of ageing. The results of this study showed how the initial design concept theorised by researchers in these projects evolved over time as a result of the increasing appropriation of the technologies developed. The findings also challenged some possible ways in which we might be tempted to both think about older people in HCI and frame the research, and showed the role of community in conducting effective $\mathrm{HCI}$ research and design with them. 
Prompted by these results, and drawing upon an analysis of different discourses and trends that are making inroads into HCI (e.g. appropriation, infrastructuring, situated epistemological theories), we have introduced a turn to community as an alternative way of thinking about and doing HCI research and design with older people. The proposed turn invites us to adopt a situated lens on the social category of older people by looking at the communities in which they engage on the basis of their interests, skills, needs, goals, selfidentities, and contingencies of daily life and life transitions.

Adopting a turn to community encourages researchers to refrain from setting up a group of older people based solely on their chronological age. Instead, it encourages researchers to engage in existing communities to which older people belong, which is a point of departure in order to tackle the challenges of working with a heterogeneous population in a pragmatic way.

The turn to community invites us to re-consider the universal design goals attached to older people (e.g., reduce social isolation and foster independent living) and to reframe such goals according to the needs/interests of the community to which older people belong. . The turn to community also encourages $\mathrm{HCI}$ researchers to be more concerned about technology appropriation, as it is then when the meaning of technology is shaped in a dialogue with everyday practices. Since appropriation takes time and happens beyond the participatory design processes, the turn encourages researchers to conduct HCI studies with older people over extended periods of time.

Finally, the turn to community pushes forward the field of HCI with older people by encouraging researchers to explore design spaces that have hitherto received scant attention in this field, such as civic tech.

We aim to conduct future research to expand, validate and show the impact of the turn to community in studies that address design goals and profiles of users different from the ones presented in this paper.

\section{Acknowledgments}

The authors are indebted to all the participants who took part in our study for having allowed us to become members and feel part of their communities. This research has been partially funded by the Spanish Ministry of Economy and Competitiveness (RESET TIN2014-53199-C3-3-R), the EU through Life2.0 (CIP ICT PSP2009-4-270965), and Fundación General CSIC and Obra Social "la Caixa" through the WorthPlay project. The authors also acknowledge the suggestions and comments made by the reviewers. The authors thank Dr. Paula Forbes for proof-reading this paper and helping us to improve our ideas.

\section{References}

Balestrini, M., Rogers, Y., Hassan, C., Creus, J., King, M., \& Marshall, P. (2017). A city in common: a framework to orchestrate large-scale citizen engagement around urban issues. In Proceedings of the 2017 CHI Conference on Human Factors in Computing Systems (pp. 2282-2294). ACM.

Bannon, L. 1991. From human factors to human actors: The role of psychology and human-computer interaction studies in systems design. In Greenbaum J. and Kyng, M. (Eds.). Design at Work: Cooperative Design of Computer Systems. Lawrence Erlbaum Associates, pp. 25-44.

Bannon, L.J. and Ehn, P., 2012. Design matters in participatory design. In Simonsen, J. and Robertson, T. (eds). International Handbook of Participatory Design. Oxford: Routledge, 37-63.

Bardzell, S. and Bardzell, J., 2011. Towards a feminist HCI methodology: social science, feminism, and HCI. In Proceedings of the SIGCHI Conference on Human Factors in Computing Systems, 675-684. May 7-12, Vancouver, Canada. ACM.

Bengtson, V.L., Gans, D., Putney, N.M., Silverstein, M., (Eds.). 2009. Theories about age and aging. In Handbook of Theories of Aging, $2^{\text {nd }}$ edition, 3-23. Springer Publishing Company, New York .

Bidwell, N.J., Siya, M., Marsden, G., Tucker, W.D., Tshemese, M., Gaven, N., Ntlangano, S., Robinson, S. and Eglinton, K.A., 2013. Walking and the social life of solar charging in rural Africa. $A C M$ Transactions on Computer-Human Interaction (TOCHI) - Special issue on practice-oriented approaches to sustainable HCI, 20(4), 22. 
Bijker, W. E., Hughes, T. P., \& Pinch, T. (Eds.) 1989. The Social Construction of Technological Systems. New Directions in the Sociology and History of Technology. MIT Press

Binder, T., De Michelis, G., Ehn, P., Jacucci, G., Linde, P. and Wagner, I., 2012. What is the object of design?. In CHI'12 Extended Abstracts on Human Factors in Computing Systems, 21-30. May 5-10, 2012. Austin, Texas, USA. ACM.

Bjögvinsson, E., Ehn, P. and Hillgren, P.A. 2012. Design things and design thinking: Contemporary participatory design challenges. Design Issues, 28(3), 101-116.

Brandt, E., Binder, T., Malmborg, L., \& Sokoler, T. 2010. Communities of everyday practice and situated elderliness as an approach to co-design for senior interaction. In Proceedings of the 22nd Conference of the Computer-Human Interaction Special Interest Group of Australia on Computer-Human Interaction - OZCHI '10 , 400-403. November 22 - 26, Brisbane, Australia. ACM.

Braun, V. and Clarke, V. 2006. Using thematic analysis in psychology. Qualitative research in psychology, 3(2), 77-101Bødker, S. 2006. When second wave HCI meets third wave challenges. In Proceedings of the 4th Nordic conference on Human-computer interaction: changing roles, 1-8. October 14-18, 2006, Oslo, Norway. ACM.

Boehner, K., \& DiSalvo, C. (2016). Data, Design and Civics: An Exploratory Study of Civic Tech. In Proceedings of the 2016 CHI Conference on Human Factors in Computing Systems (pp. 2970-2981). ACM.

Boyatzis, R. E. 1998. Transforming qualitative information: Thematic analysis and code development. Thousand Oaks, CA:Sage.

Bond, J., Peace, S. M., Dittmann-Kohli, F., \& Westerhof, G. (Eds.). (2007). Ageing in society. Sage.

Botero, A. and Hyysalo, S., 2013. Ageing together: Steps towards evolutionary co-design in everyday practices. CoDesign, 9(1), 37-54.

Bødker, S. 2006. When second wave HCI meets third wave challenges. In Proceedings of the 4th Nordic conference on Human-computer interaction: changing roles, 1-8. October 14-18, 2006, Oslo, Norway. ACM.

Bødker, S. and Christiansen, E., 2012. Poetry in motion: appropriation of the world of apps. In Proceedings of the 30th European conference on cognitive ergonomics, 78-84. August 28-31, Edinburgh, Scotland, ACM.

Bytheway, B. 1997. Ageism. Open university Press, Buckingham.

Cabrero, D., Winschiers, T.H., Abdelnour N.J., (2016) A Critique of Personas as representations of "the other" in Cross-Cultural Technology Design. To appear in the proceedings of AfriCHI'16 Nov. 21-25, 2016, Nairobi, Kenya

Calvo, R. \& Peters, D., 2014. Positive Computing. Technology for Wellbeing and Human Potential, The MIT Press.

Carroll, J., Howard, S., Vetere, F., Peck, J., \& Murphy, J. 2001. Identity, power and fragmentation in cyberspace: technology appropriation by young people. In ACIS 2001 Proceedings, Paper 6.

Carroll, J. M., Convertino, G., Farooq, U., and Rosson, M. B. 2011. The firekeepers: aging considered as a resource. Universal Access in the Information Society, 11(1), 7-15.

Chiou, E., Venkatraman, V., Larson, K., Li, Y., Gibson, M., \& Lee, J. D. (2014). Contextual design of a motivated medication management device. Ergonomics in Design: The Quarterly of Human Factors Applications, 22(1), 8-15.

Compagna, D., and Kohlbacher, F. 2015. The limits of participatory technology development: The case of service robots in care facilities for older people. Technological Forecasting and Social Change, 93, 1931. 
Cornejo, R., Tentori, M. \& Favela, J., 2013. Enriching in-person encounters through social media: A study on family connectedness for the elderly. International Journal of Human-Computer Studies, 71(9), pp.889-899.

Crabtree, A. et al. (2000) "Ethnomethodologically-informed ethnography in information systems design", JASIS, vol. 51 (7), pp. 666-682.

Czaja, S.J., 1990. Human factors research needs for an aging population. National Academies Press.

Czaja, S. J., and Lee, C. C. 2007. The impact of aging on access to technology. Universal Access in the Information Society, 5(4):341-349.

Degnen, C. 2007. Minding the gap: The construction of old age and oldness amongst peers. Journal of Aging Studies, 21(1): 69-80.

DeWalt, K. M., and DeWalt, B. R., 2010. Participant Observation: A Guide for Fieldworkers. Oxford: AltaMira Press, Rowman \& Littlefield Publishers, Inc.

DiSalvo, C., Clement, A., and Pipek, V. 2013. Participatory design for, with, and by communities. In Simonsen, J. and Robertson, T. (eds). International Handbook of Participatory Design. Oxford: Routledge, pp. 182-209.

Dodson, L.L., Sterling, S. and Bennett, J.K., 2012, March. Considering failure: eight years of ITID research. In Proceedings of the Fifth International Conference on Information and Communication Technologies and Development, 56-64. March 12-15, Atlanta, USA. ACM.

Dourish, P. 2001. Where the action is: the foundations of embodied interaction. Cambridge: MIT press.

Dourish, P. 2004. What we talk about when we talk about context. Personal and ubiquitous computing, 8 (1): 19-30.

Dourish, P., and Mainwaring, S. D. 2012. Ubicomp's colonial impulse. In Proceedings of the 2012 ACM Conference on Ubiquitous Computing, 133-142. Sep 5-8, Pittsburgh, USA.

Durick, J., Robertson, T., Brereton, M., Vetere, F. and Nansen, B. 2013. Dispelling ageing myths in technology design. In Proceedings of the 25th Australian Computer-Human Interaction Conference: Augmentation, Application, Innovation, Collaboration, 467-476. November 23-29, 2013, Adelaida, Australia. ACM.

Ehn, P. 2008. Participation in design things. In Proceedings of the 10th biennal Anniversary Conference on Participatory Design, PDC 2008, 92-101. October 1-5, 2008, Bloomington, Indiana, USA. ACM

Fetterman, D.M. 2010. Ethnography: Step-by-step. 3rd ed. SAGE Publications, Inc.

Fisk, A.D. and Rogers, W.A. (Eds.). 1997. Handbook of human factors and the older adult. Academic Press, San Diego, USA.

Fisk, A. D., Rogers, W. A., Charness, N., Czaja, S. J., \& Sharit, J. (2009). Designing for older adults: Principles and creative human factors approaches. CRC press.

Gaver, W., Blythe, M., Boucher, A., Jarvis, N., Bowers, J. and Wright, P. 2010. The prayer companion: openness and specificity, materiality and spirituality. In Proceedings of the SIGCHI conference on Human factors in computing systems, 2055-2064. April 10-15 2010, Atlanta, GA, USA. ACM

Gerling, K. M., Schild, J., and Masuch, M. 2010. Exergame design for elderly users: the case study of SilverBalance. In Proceedings of the 7th International Conference on Advances in Computer Entertainment Technology, 66-69. November 17-19, Taipei, Taiwan. ACM.

Gregor, P., \& Newell, A. F. 2001. Designing for Dynamic Diversity - Making accessible interfaces for older people. In WUAUC (pp. 90-92). Alcácer do Sal, Portugal.

Gregor, P., Newell, A.F. and Zajicek, M. 2002. Designing for dynamic diversity: interfaces for older people. In Proceedings of the fifth international ACM conference on Assistive technologies, 151-156. July 810, 2002 Edinburgh, Scotland. ACM. 
Haraway D., 1988. Situated Knowledges: The Science Question in Feminism and the Privilege of Partial Perspective. Feminist Studies, 14(3), 575-599.

Harrison, S., Tatar, D. and Sengers, P., 2007. The three paradigms of HCI. In Alt. Chi. Session at the SIGCHI Conference on Human Factors in Computing Systems, 1-18. April 28 - May 3, 2007, San Jose, USA. $\mathrm{ACM}$

Harrison, S., Sengers, P. and Tatar, D. 2011. Making epistemological trouble: Third-paradigm HCI as successor science. Interacting with Computers, 23(5), 385-392.

Hassenzahl, M., \& Tractinsky, N. (2006). User experience-a research agenda. Behaviour \& information technology, 25(2), 91-97.

Hassenzahl, M. (2010). Experience design: Technology for all the right reasons. Synthesis Lectures on Human-Centered Informatics, 3(1), 1-95.

Hill, R., Betts, L. R., \& Gardner, S. E. 2015. Older adults' experiences and perceptions of digital technology:(Dis) empowerment, wellbeing, and inclusion. Computers in Human Behavior, 48, 415423.

Hyysalo, S. 2006. Representations of Use and Practice-Bound Imaginaries in Automating the Safety of the Elderly. Social Studies of Science, 36(4), 599-626.

Hofer, S. M., \& Alwin, D. F. (Eds.). (2008). Handbook of cognitive aging: Interdisciplinary perspectives. Sage Publications.

Holtzblatt, K., \& Beyer, H. (2014). Contextual Design: Evolved. Synthesis Lectures on Human-Centered Informatics, 7(4), 1-91.

Hornung, D., Müller, C., Shklovski, I., Jakobi, T., \& Wulf, V. 2017. Navigating Relationships and Boundaries: Concerns around ICT-uptake for Elderly People. In Proceedings of the 2017 CHI Conference on Human Factors in Computing Systems (pp. 7057-7069). ACM.

Irani, L., Vertesi, J., Dourish, P., Philip, K., \& Grinter, R. E. 2010. Postcolonial computing: a lens on design and development. In Proceedings of the SIGCHI Conference on Human Factors in Computing Systems, 1311-1320. April 10-15, Atlanta, USA. ACM.

Jasanoff, S. (Ed.). 2004. States of knowledge: the co-production of science and the social order. Routledge.

Jonsson, O. 2013. Furniture for Later Life: Design Based on Older People's Experiences of Furniture in Three Housing Forms, PhD diss. University, Dept. Design Sciences, Div. of Industrial Design, Lund, Sweden.

Joyce, K. and Mamo, L. 2006. Graying the cyborg: New directions in feminist analyses of aging, science, and technology In Calasanti, T. M., and Slevin, K. F. (Eds.) Age matters: Realigning feminist thinking, 99-121. Routledge, Taylor \& Francis Group.

Kapuire, G.K., Winschiers-Theophilus, H. and Blake, E. 2015. An insider perspective on community gains: A subjective account of a Namibian rural communities' perception of a long-term participatory design project. International Journal of Human-Computer Studies, 74, 124-143.

Karasti, H. and Syrjänen, A.L. 2004. Artful infrastructuring in two cases of community PD. In Proceedings of the eighth conference on Participatory design: Artful integration: interweaving media, materials and practices-Volume 1, 20-30. July 27-31, 2004, Toronto, Canada. ACM.

Khoo, E., Merritt, T., \& Cheok, A. 2009. Designing physical and social intergenerational family entertainment. Interacting with Computers, 21(1-2), 76-87.

Kukka, H., Ylipulli, J., Luusua, A., Dey, A. K. 2014. Urban Computing in Theory and Practice : Towards a Transdisciplinary Approach. In Proceedings of the 8th Nordic Conference on Human-Computer Interaction: Fun, Fast, Foundational, 658-667. October 23-27, Gothenburg, Sweden. ACM. 
Kuutti, K., \& Bannon, L. J. 2014. The turn to practice in HCI: towards a research agenda. In Proceedings of the 32nd annual ACM conference on Human factors in computing systems, April 26 - May1, Toronto, Canada, pp. 3543-3552. ACM.

Laslett, P. 1991. A fresh map of life: The emergence of the third age. Cambridge, Massachusetts: Harvard University Press.

Lawson, S. W., Nutter, D., and Wilson, P. 2007. Design of interactive technology for ageing-in-place. In Universal Acess in Human Computer Interaction. Coping with Diversity, 960-967. Springer Berlin Heidelberg.

Le Dantec, C.A. and DiSalvo, C., 2013. Infrastructuring and the formation of publics in participatory design. Social Studies of Science, 43(2): 241-264.

Lee, Y. 2012. The Ingenuity of Ageing: For Designing Social Innovation. Royal College of Art.

Light, A., Leong, T.W. and Robertson, T. 2015. Ageing Well with CSCW. In ECSCW 2015: Proceedings of the 14th European Conference on Computer Supported Cooperative Work, 295- 304. September 19-23, 2015, Oslo, Norway. Springer International Publishing.

Lund, A. and Engelsrud, G. 2008. 'I am not that old': inter-personal experiences of thriving and threats at a senior centre. Ageing and Society, 28(5), 675-692

MacLean, A., Young, R., Bellotti, V. and Moran, T. 1991. Design space analysis: Bridging from theory to practice via design rationale. Proceedings of Esprit '91, Nov. 25-29, Brussels, Belgium, pp.720-730.

Malmborg, L. and Yndigegn, S.L., 2013. Sustainable infrastructure for ad hoc social interaction. In Brandt, E., Ehn, P., Johansson, T. D., Reimer, M. H., Markussen, T. \& Vallgårda, A. (eds.) Nordes 2013: Experiments in design research. Kunstakademiets Arkitektskolens Forlag, pp. 228-237.

Marsden, G., Maunder, A., \& Parker, M. 2008. People are people, but technology is not technology. Philosophical Transactions of the Royal Society of London, 366, 3795-3804.

Marttila, S. and Botero, A., 2013. The 'Openness Turn' in Co-design. From Usability, Sociability and Designability Towards Openness. In Smeds \& Irrmann (eds.). CO-CREATE 2013 - The BoundaryCrossing Conference on Co-Design in Innovation, 99-110. June 16-19, 2013, Espoo, Finland.

McNeill, A. R., Coventry, L., Pywell, J., \& Briggs, P. 2017. Privacy Considerations when Designing Social Network Systems to Support Successful Ageing. In Proceedings of the 2017 CHI Conference on Human Factors in Computing Systems (pp. 6425-6437). ACM.

Millen, D.R., 2000. Rapid ethnography: time deepening strategies for HCI field research. In Proceedings of the 3rd conference on Designing interactive systems: processes, practices, methods, and techniques, 280-286. August 17-19, NY, USA, ACM.

Neven, L. 2010. "But obviously not for me": robots, laboratories and the defiant identity of elder test users. Sociology of Health \& Illness, 32(2), 335-47.

Neven, L., 2015. By any means? Questioning the link between gerontechnological innovation and older people's wish to live at home. Technological forecasting and social change, 93, 32-43.

Östlund, B., Olander, E., Jonsson, O., \& Frennert, S. 2015. STS-inspired design to meet the challenges of modern aging. Welfare technology as a tool to promote user driven innovations or another way to keep older users hostage? Technological Forecasting and Social Change, 93, 82-90

Peine, A., Rollwagen, I. and Neven, L. 2014. The rise of the "innosumer"-rethinking older technology users. Technological Forecasting and Social Change, 82, 199-214.

Peine, A., Faulkner, A., Jæger, B. and Moors, E. 2015. Science, technology and the 'grand challenge'of ageing - Understanding the socio-material constitution of later life. Technological Forecasting and Social Change, 93: 1-9.

Persson, H., Åhman, H., Yngling, A.A. and Gulliksen, J., 2014. Universal design, inclusive design, accessible design, design for all: different concepts — one goal? On the concept of accessibility- 
historical, methodological and philosophical aspects. Universal Access in the Information Society, 14(4):505-506.

Phillipson, C. 2008. Reconstructing theories of ageing: the impact of globalization on critical gerontology. In Bengston, V.L, Gans, D., Putney, N., Silverstein, M. (eds). Handbook of Theories of Ageing. 2nd ed, 615-628. Springer Publishing Company, LLC

Redström, J. 2006. Towards user design? On the shift from object to user as the subject of design. Design studies, 27(2), 123-139.

Righi, V., Sayago S., Blat, J. 2015. Urban ageing: technology, agency and community in smarter cities for older people. In Proceedings of the $7^{\text {th }}$ International Conference on Communities and Technologies (C\&T 2015), 119-128. June 27-30, Limerick, Ireland. ACM Press.

Rodeschini, G., 2011. Gerotechnology: A new kind of care for aging? An analysis of the relationship between older people and technology. Nursing \& health sciences, 13(4), 521-528.

Rogers, Y. (2011) Interaction design gone wild: striving for wild theory. interactions, 18(4): 58-62.

Rogers, Y. 2012. HCI theory: classical, modern, and contemporary. Carroll J.M. (ed.). Synthesis Lectures on Human-Centered Informatics. Morgan \& Claypool Publishers.

Rogers, Y. and Marsden, G., 2013. Does he take sugar?: moving beyond the rhetoric of compassion. interactions, 20(4), 48-57. ACM

Rogers, Y., Paay, J., Brereton, M., Vaisutis, K.L., Marsden, G. and Vetere, F., 2014. Never too old: engaging retired people inventing the future with MaKey MaKey. In Proceedings of the SIGCHI Conference on Human Factors in Computing Systems, 3913-3922. April 26 - May 1, 2014, Toronto, Canada. ACM.

Salovaara, A., Lehmuskallio, A., Hedman, L., Valkonen, P. and Näsänen, J., 2010. Information technologies and transitions in the lives of 55-65-year-olds: The case of colliding life interests. International journal of human-computer studies, 68(11), 803-821.

Salovaara, A., Helfenstein, S. and Oulasvirta, A., 2011. Everyday appropriations of information technology: A study of creative uses of digital cameras. Journal of the American Society for Information Science and Technology, 62(12), 2347-2363.

Sayago, S. 2009 Human-Computer Interaction with Older People: From Factors to Social Actors. Ph.D. diss., Universitat Pompeu Fabra.

Sayago, S., Blat, J., 2010. Telling the story of older people emailing: an ethnographical study, International Journal of Human-Computer Studies, 68, 105-120

Sayago, S., Sloan, D., \& Blat, J. (2011). Everyday use of computer-mediated communication tools and its evolution over time: An ethnographical study with older people. Interacting with Computers, 23(5), 543-554.

Sayago, S., Rosales, A., Righi, V., Ferreira, S., Coleman, G., Blat, J. 2016. On the Conceptualization, Design and Evaluation of Appealing, Meaningful and Playable Digital Games for Older People. Games and Culture, 11(1-2), 53-80.

Schaie, K. W., \& Willis, S. L. (2011). Handbook of the psychology of aging. Elsevier Inc..

Storni, C. 2010. Multiple forms of appropriation in self-monitoring technology: reflections on the role of evaluation in future self-care. Intl. Journal of Human-Computer Interaction, 26(5), 537-561

Suchman, L. 1987. Plans and situated actions: The Problem of Human-Machine Communication. Cambridge University Press, New York.

Suchman, L., 2011. Anthropological relocations and the limits of design. Annual Review of Anthropology, 40,1-18.

Taylor, A.S., 2011. Out there. In Proceedings of the SIGCHI Conference on Human Factors in Computing Systems, 685-694. May 7-11, Vancouver, Canada. ACM. 
Trewin, S., Richards, J. T., Hanson, V. L., Sloan, D., John, B. E., Swart, C., \& Thomas, J. C. (2012). Understanding the Role of Age and Fluid Intelligence in Information Search. In ASSETS (pp. 119-126). Boulder, Colorado.

Vetere, F. et al., 2009. The Magic Box and Collage: Responding to the challenge of distributed intergenerational play. International Journal of Human-Computer Studies, 67(2), pp.165-178.

Vines, J., Pritchard, G., Wright, P., Olivier, P., and Brittain, K. 2015. An Age-Old Problem: Examining the Discourses of Ageing in HCI and Strategies for Future Research. ACM Transactions on ComputerHuman Interaction (TOCHI), 22(1), Article 2, 1-27.

Walke,r A. 1981. Towards a Political Economy of Old Age. Ageing and Society, 1,73-94

Wildevuur, S., van Dijk, D., Hammer-Jakobsen, T., Bjerre, M., Äyväri, A., and Lund, J. (eds.). 2013. Connect. Design for an empathic society. BIS Publishers

Williams, A., Robles, E., \& Dourish, P. 2009. Urbane-ing the city: Examining and refining the assumptions behind urban informatics. In Foth (ed.), Handbook of Research on Urban Informatics: The Practice and Promise of the Real-Time City. Hershey, PA: Information Science Reference, IGI Global, pp. 1-20

Wright, P., \& McCarthy, J. (2010). Experience-centered design: designers, users, and communities in dialogue. Synthesis Lectures on Human-Centered Informatics, 3(1), 1-123.

\section{Appendix I - Detailed overview of research activities}

This appendix includes three tables that present a detailed and succinct account of the research activities conducted during the two R\&D projects, Life 2.0 and WorthPlay. Each table is related to a specific phase of the projects, i.e. analysis, conceptualization and evaluation. Each table presents a short description of the activity, the methods conducted and the approximate number of participants and hours of fieldwork.

Life 2.0

\begin{tabular}{|c|c|c|}
\hline Activity and methods & Total hours & Participants \\
\hline $\begin{array}{l}\text { Participant observations and conversations in } 5 \text { Basic-ICT } \\
\text { courses which were carried out by Àgora volunteers, and } 1 \\
\text { Advanced-ICT course that we set up and ran. In the Basic-ICT } \\
\text { course, participants learnt to use Microsoft Word, Power Point } \\
\text { and e-mail, and in the Advanced-ICT course they learnt Google } \\
\text { Maps, Youtube, Facebook, Blogger, among others. }\end{array}$ & $\begin{array}{l}82 \mathrm{~h} \text { (average of } \\
14 \mathrm{~h} \text { in each } \\
\text { course) }\end{array}$ & $\begin{array}{l}75,10 \text { of them participating in } \\
\text { more than one course. }\end{array}$ \\
\hline $\begin{array}{l}\text { Focus group aimed at eliciting participants' life stories and daily } \\
\text { routines. }\end{array}$ & $2 \mathrm{~h}$ & $\begin{array}{l}8 \text {, all of them participated in at } \\
\text { least } 1 \text { ICT course in which I } \\
\text { conducted observations. }\end{array}$ \\
\hline $\begin{array}{l}\text { Diaries - participants were asked to fill in a diary structured to } \\
\text { elicit a brief description of their everyday activities, conducted } \\
\text { outside or inside their home, with or without technologies and } \\
\text { with or without the company of friends and relatives. }\end{array}$ & $\begin{array}{l}\text { Participants } \\
\text { kept the diary } \\
\text { for } 1 \text { week }\end{array}$ & $\begin{array}{l}8,6 \text { of them participated in the } \\
\text { focus group. All of them } \\
\text { participated in at least } 1 \text { ICT } \\
\text { course in which we conducted } \\
\text { observations. }\end{array}$ \\
\hline $\begin{array}{l}\text { Interview to the director of social services of the local area. The } \\
\text { interview aimed to get an overview of the public services } \\
\text { offered to older people and general issues regarding them. }\end{array}$ & $1 \mathrm{~h}$ & $\begin{array}{l}1 \text { representative of the caregiver } \\
\text { sector. }\end{array}$ \\
\hline \multicolumn{3}{|l|}{ WorthPlay } \\
\hline Activity and methods & Total hours & Participants \\
\hline $\begin{array}{l}\text { Participant observations and informal conversations in Playing } \\
\text { Clubs that we set up in Àgora. The group met once per week to }\end{array}$ & $48 \mathrm{~h}$ & 8 \\
\hline
\end{tabular}




\begin{tabular}{|l|l|l|}
\hline play different types of digital and tabletop games. & \\
\hline $\begin{array}{l}\text { Participant observations and informal conversations in extra- } \\
\text { curriculum activities in 8 Àgora courses. The courses varied } \\
\text { from Internet, literacy, literature and English. }\end{array}$ & $\begin{array}{l}\text { 24h (average of } \\
3 \mathrm{~h} \text { in each } \\
\text { course) }\end{array}$ & 152 \\
\hline $\begin{array}{l}\text { Participant observations and informal conversations in a } \\
\text { workshop (3 sessions) on Smartphone. The goal was to explore } \\
\text { participants' use of different applications for gamified activities } \\
\text { (e.g. Endomondo). }\end{array}$ & $\begin{array}{l}10,5 \text { of them were participants } \\
\text { of the Playing Clubs }\end{array}$ \\
\hline
\end{tabular}

Table 3. Fieldwork activities carried out in the analysis phase of Life 2.0 and WorthPlay projects.

Life 2.0

\begin{tabular}{|c|c|c|}
\hline Activity and methods & Total hours & Participants \\
\hline $\begin{array}{l}\text { Debriefing session to discuss and validate the results of the } \\
\text { rapid ethnographical study, which aimed at informing the co- } \\
\text { design phase. }\end{array}$ & $2 \mathrm{~h}$ & $\begin{array}{l}20 \text { participants who already } \\
\text { participated in the previous } \\
\text { phase. }\end{array}$ \\
\hline $\begin{array}{l}\text { Co-design workshop in which, through storytelling and } \\
\text { personas \& scenarios techniques, we aimed to elicit scenarios } \\
\text { for future services. }\end{array}$ & $2 \mathrm{~h}$ & 10 \\
\hline $\begin{array}{l}\text { Co-design workshop in which } 3 \text { scenarios, which were selected } \\
\text { by the consortium partners on the basis of the ethnographical } \\
\text { studies and the previous co-design activities, were presented to } \\
\text { participants in order to elicit positive and negative aspects, } \\
\text { variations of the scenarios and collect requirements. The } \\
\text { scenarios were presented through storytelling in order to } \\
\text { facilitate their comprehension. The discussion was then fostered } \\
\text { through questions that tried to cover all the stages and } \\
\text { functionalities of the scenarios. Post-its were used to } \\
\text { collaboratively write down positive and negative aspects of the } \\
\text { scenarios and encourage contributions from participants. }\end{array}$ & $3 \mathrm{~h}$ & 9 \\
\hline $\begin{array}{l}\text { Weekly meetings with a core group of project participants were } \\
\text { conducted from March } 2012 \text { to September } 2013 \text {. About } 35 \% \text { of } \\
\text { these meetings intended to discuss the platform design and } \\
\text { service concept. This was done through informal conversations } \\
\text { and / or sketching sessions. Fifteen percent of the meetings were } \\
\text { aimed at training participants to use the prototype developed. In } \\
\text { the rest of the meetings participants were learning to use } \\
\text { mainstream technologies, related with the project goals (e.g. } \\
\text { Social Networks Sites as Facebook, Twitter and social } \\
\text { communication tools such as WhatsApp). These activities were } \\
\text { aimed at getting a first-hand understanding of participants' } \\
\text { attitudes towards and use of the platform and the service } \\
\text { concept and identify design improvements. }\end{array}$ & $\begin{array}{l}\text { 100h, of which } \\
\text { c. } 35 \mathrm{~h} \\
\text { expressively } \\
\text { dedicated to } \\
\text { discuss design } \\
\text { and use of the } \\
\text { platform }\end{array}$ & $\begin{array}{l}24,18 \text { of them participated } \\
\text { continuously; the rest attended } \\
\text { the meetings for maximum } 3 \\
\text { months. }\end{array}$ \\
\hline \multicolumn{3}{|l|}{ WorthPlay } \\
\hline Activity and methods & Total hours & Participants \\
\hline $\begin{array}{l}\text { A game about neighbourhood memories. The game was created } \\
\text { by participants of the Playing Club. It was then played in an } \\
\text { Advanced-ICT course and during a summer party event } \\
\text { organized by Agora. In these scenarios / contexts of ICT use, } \\
\text { participants added new contents to the game. In this activity we } \\
\text { looked into how to have older people involved in the creation of } \\
\text { digital games, including the rules of the game and its contents. } \\
\text { The whole activity developed into } 3 \text { sessions. }\end{array}$ & $\begin{array}{l}\text { 7h for creating } \\
\text { and playing the } \\
\text { game }\end{array}$ & $\begin{array}{l}18 \text { participants created the first } \\
\text { version of the game } \\
\text { c. } 80 \text { participants played the } \\
\text { game and added new contents to } \\
\text { it. }\end{array}$ \\
\hline
\end{tabular}




\begin{tabular}{|c|c|c|}
\hline $\begin{array}{l}\text { A geo-located quiz about a book. The game was created and } \\
\text { played by participants of a book-reading club in Àgora. In this } \\
\text { activity we aimed to understand the degree to which older } \\
\text { people can be interested in participating in a physical and } \\
\text { playful activity combining mobile devices and geo-localized } \\
\text { technologies. The whole activity developed in } 4 \text { sessions. }\end{array}$ & $\begin{array}{l}7.5 \mathrm{~h} \text { for creating } \\
\text { and playing the } \\
\text { game }\end{array}$ & $\begin{array}{l}20 \text { participants created and } \\
\text { played the game }\end{array}$ \\
\hline $\begin{array}{l}\text { A trivia quiz about Spanish folk parties. The game was created } \\
\text { by participants of the Playing Club and played in an Advanced- } \\
\text { ICT class. In this activity we intended to explore the idea of } \\
\text { conducting simple playful activities with non-gamers addressing } \\
\text { a well-known topic. The whole activity developed into } 2 \\
\text { sessions. }\end{array}$ & $\begin{array}{l}\text { 4h for creating } \\
\text { and playing the } \\
\text { game }\end{array}$ & $\begin{array}{l}5 \text { participants created the game } \\
18 \text { participants played it. }\end{array}$ \\
\hline
\end{tabular}

Table 4. Fieldwork activities carried out in the conceptualization phase of Life 2.0 and WorthPlay projects.

\section{Life 2.0}

\begin{tabular}{|c|c|c|}
\hline Activity and methods & Total hours & Participants \\
\hline $\begin{array}{l}\text { Weekly meetings with a core group of project participants - See } \\
\text { Table } 2 .\end{array}$ & See Table 2. & See Table 2. \\
\hline $\begin{array}{l}\text { Questionnaires aimed at collecting demographic data and } \\
\text { overall satisfaction with the developed platform and related } \\
\text { services. Participants' opinions about the questionnaire answers } \\
\text { were debated in an informal } 15 \text { minutes group discussion. }\end{array}$ & $\begin{array}{l}15 \mathrm{~min} \text { of group } \\
\text { discussion }\end{array}$ & 18 \\
\hline $\begin{array}{l}\text { Through dissemination activities carried out by the research } \\
\text { team and / or the same participants, we gathered additional } \\
\text { opinions of other older people who were not directly involved in } \\
\text { the project and other potential stakeholders. }\end{array}$ & $\begin{array}{l}\text { Approximately } \\
25 \mathrm{~h}\end{array}$ & $\begin{array}{l}\text { Around } 40 \text { older people - not } \\
\text { previous participants of the } \\
\text { project; } 18 \text { older people - } \\
\text { participants of the project; } \\
\text { representatives of } 2 \\
\text { governmental organizations, } 2 \\
\text { businesses and } 11 \text { associations - } \\
\text { including } 2 \text { time banking } \\
\text { groups. }\end{array}$ \\
\hline $\begin{array}{l}\text { Two debriefing sessions, at the middle and at the end of the } \\
\text { evaluation period. Researchers briefly presented a summary of } \\
\text { the results and discussed them with the participants to further } \\
\text { elaborate on, and/or validate them. }\end{array}$ & $4 \mathrm{~h}$ & 18 \\
\hline \multicolumn{3}{|l|}{ WorthPlay } \\
\hline Activity and methods & Total hours & Participants \\
\hline $\begin{array}{l}\text { Neighbourhood game in a public event. The game, which was } \\
\text { about the memories of the Àgora neighbourhood, was created } \\
\text { and played in previous participatory design sessions. This time } \\
\text { it was played on the gaming platform, by using tablets. }\end{array}$ & $2.5 \mathrm{~h}$ & 20 \\
\hline $\begin{array}{l}\text { Games in General Knowledge course. } 4 \text { quiz games were } \\
\text { created; one game was created by the teacher while the rest by } \\
\text { the participants of the course. The participants were free to } \\
\text { decide the topics of the games. All the games were about the } \\
\text { contents learned during the course. The activity developed in } 7 \\
\text { sessions. }\end{array}$ & $8.5 \mathrm{~h}$ & 14 \\
\hline $\begin{array}{l}\text { Neighbourhood game in two ICT courses. Two different courses } \\
\text { on ICT participated in the activity, which was about playing a } \\
\text { game created by some of Àgora participants in previous co- } \\
\text { design activities. As the participants were completing the game, } \\
\text { the researchers invited them to create and add new questions to }\end{array}$ & $\begin{array}{l}5 \mathrm{~h}(2.5 \mathrm{~h} \text { in each } \\
\text { course })\end{array}$ & 24 \\
\hline
\end{tabular}




\begin{tabular}{|l|l|l|}
\hline the game. & & \\
\hline $\begin{array}{l}\text { Games in literary gathering, a geo-located quiz about the life } \\
\text { and works of the Catalan writer Bernat Metge. The activity } \\
\text { developed in 5 sessions. }\end{array}$ & & 9 \\
\hline
\end{tabular}

Table 5. Fieldwork activities carried out in the evaluation phase of Life 2.0 and WorthPlay projects. 